\title{
Correlation of Clinical Neuromusculoskeletal and Central Somatosensory Performance: Variability in Controls and Patients with Severe and Mild Focal Hand Dystonia
}

\author{
Nancy N. Byl, ${ }^{1}$ Srikantan S. Nagarajan, ${ }^{2}$ Michael M. Merzenich, ${ }^{3}$ Tim Roberts ${ }^{2}$ and Alison McKenzie ${ }^{4}$ \\ ${ }^{1}$ Dept. of Physical Therapy \& Rehabilitation Science, School of Medicine; ${ }^{2}$ Dept. of Radiology, \\ Bioimaging Laboratory; ${ }^{3}$ Dept. of Otolaryngology \& Dept. of Physiology, Coleman Laboratory \& Keck \\ Center for Neuroscience Research University of California, San Francisco, California, USA; \\ ${ }^{4}$ Dept. of Physical Therapy, Chapman University, Orange, California, USA;
}

\begin{abstract}
SUMMARY
Focal hand dystonia (FHd) is a recalcitrant, disabling movement disorder, characterized by involuntary co-contractions of agonists and antagonists, that can develop in patients who overuse or misuse their hands. The aim of this study was to document clinical neuromusculoskeletal performance and somatosensory responses (magnetoencephalography) in healthy controls and in FHd subjects with mild versus severe hand dystonia. The performance of healthy subjects $(n=17)$ was significantly better than that of FHd subjects $(n=17)$ on all clinical parameters. Those with mild dystonia $(\mathrm{n}=10)$ demonstrated better musculoskeletal skills, task-specific motor performance, and sensory discrimination, but the performance of sensory and fine motor tasks was slower than that of patients with severe dystonia. In terms of somatosensory evoked field responses (SEFs), FHd subjects demonstrated a significant difference in the location of the hand representation on the $x$ and $y$ axes, lower amplitude of SEFs integrated across latency,
\end{abstract}

Reprint requests to: Nancy N. Byl, PhD, MPH, PT, FAPTA, 1360 9th Ave. Box 0736, Dept. of Physical Therapy \& Rehabilitation Science, University of California, San Francisco, CA 94143-0736, USA byläitsa.ucsf.edu and a higher ratio of mean SEF amplitude to latency than the controls. Bilaterally, those with FHd (mild and severe) lacked progressive sequencing of the digits from inferior to superior. On the affected digits, subjects with severe dystonia had a significantly higher ratio of SEF amplitude to latency and a significantly smaller mean volume of the cortical hand representation than those with mild dystonia. Severity of dystonia positively correlated with the ratio of SEF mean amplitude to latency (0.9029 affected, 0.8477 unaffected; $p<0.01)$. The results of the present study strengthen the evidence that patients with FHd demonstrate signs of somatosensory degradation of the hand that correlates with clinical sensorimotor dysfunction, with characteristics of the dedifferentiation varying by the severity of hand dystonia. If these findings represent aberrant learning, then effective rehabilitation must incorporate the principles of neuroplasticity. Training must be individualized to each patient to rebalance the sensorimotor feedback loop and to restore normal fine motor control.

\section{KEYWORDS}

somatosensory evoked potentials, neuroplasticity, focal hand dystonia, magnetoencephalography 


\section{INTRODUCTION}

Most tasks performed with the hands require delicate, complex, individuated, fine motor movements (Gerloff et al., 1996; Johansson, 1996; Sherrington, 1906). The hand has a large, orderly, somatotopic, highly differentiated representation in the sensory and motor areas of the brain (Iwamura et al., 1983; Iwamura et al., 1992; Jenkins et al., 1988; Kass et al., 1986; Penfield, 1950; Yang et al., 1994). These topographical representations are complemented by functional representations of well- learned tasks (e.g. writing) (Rijintjes et al., 1999).

Somatotopic and functional representations are modified by injury, development, learning, environmental enrichment, deprivation, disease, and practice. Representational changes can be modified over a lifetime by attended, goaldirected, rewarded, nonstereotypic, progressive spaced practice (Jenkins et al., 1990; Wang et al., 1994). Selective changes in cell assemblies can be driven by behaviors that selectively specialize hand representations in parallel with the emergence of more efficient, accurate, and differentiated behaviors. This neural adaptation has been extensively documented in terms of modulation in neural transmitters, myelination, synaptic and dendritic complexity, as well as function in studies involving animals (Allard et al., 1991; Hebb, 1949; Jenkins et al., 1990; Jenkins et al., 1990; Kass et al., 1983; Merzenich et al., 1983 a-b, 1984, 1991; Nudo et al., 1996 a-b, 1999, 2000; Penfield, 1950; Recanzone et al., 1992a-c; Wang et al., 1994, 1995; Yang et al., 1994; Zerri et al., $1996 ; 1999$ ) and humans (Merzenich et al., 1996 ac, 1998; Elbert et al., 1998, Nagarajan et al., 1997; Sanger \& Merzenich, 2000; Spengler et al., 1997; Wright et al., 1997).

Despite the infinite degrees of freedom and permutations of a wide variety of movements, much of what we do becomes repetitive, stereotypic, and automatic. Given the limits of neural adaptation, stressful, attended, stereotypic, near-coincident, repetitions can have negative consequences on motor performance, e.g. focal hand dystonia (FHd) (Bara-Jimenez et al., 2000; Byl et al., 1996 a-b; 2000 a-b; Chen et al., 1998; Mc Kenzie et al., 2000).

Focal hand dystonia, also referred to as occupational hand cramps, is one type of focal limb dystonia (Altenmueller, 1997). Involuntary cocontractions of agonists and antagonists cause writhing and twisting movements of the hand and wrist that interfere with controlled, target specific voluntary fine motor movements (Altenmueller et al., 1997; Bell, 1883; Cohen \& Hallet, 1988; Cole et al., 1995; Fry, 1986; Hochberg et al., 1990; Jankovic \& Shale, 1989; Marsden et al., 1990; Newark et al., 1987; Rothwell et al., 1983; Tubiana, 1983; Utti et al., 1995). Etiologic factors for focal dystonia range from genetics (Gasser et al., 1996; Illarioshkin et al., 1988; Leube et al., 1996; Ozelius et al., 1997), imbalance between the inhibitory and excitatory pathways in the globus pallidus (Black et al., 1998; DeLong et al., 1985, 1990; Perlmutter et al., 1997), cortical dysfunction (Chase et al., 1988; Defendini \& Fahn, 1988; Deuschl et al., 1995; Gilman et al., 1988; Tempel, 1993; Toro, 2000), degradation of the somatotopic maps in the thalamus (Lenz et al., 1996; Utti, 1995), disruption of reciprocal inhibition at the level of the spinal cord, (Chen et al., 1995, Kaji et al., 1995; Nakashima et al., 1989; Naumann et al., 1997; Panizza et al., 1989, 1990), to secondary problems related to chronic pain, trauma, nerve root irritation, peripheral nerve entrapment, or anatomic restrictions (Charness et al., 1992; 1993; Katz et al., 1990; Leijinse. 1996; Quartarone et al., 1998; Topp \& Byl, 1999; Wilson et al., 1991; 1993).

Initial evidence from animal and human studies implies that FHd could be a consequence of aberrant learning. Repetitive, near simultaneous, alternating, reciprocal digital movements, performed under stressful conditions, can lead to de-differentiation of the somatosensory hand representation that 
disrupts sensory discrimination, sensorimotor feed back, and fine motor control (sensorimotor learning hypothesis) (Bara-Jimenez et al., 1998; Byl et al., $1996 \mathrm{a}-\mathrm{c} ; 1997 ; 2000 \mathrm{a}$-c; Ikeda et al., 1999; Odergren et al., 1996; Sanger \& Merzenich, 2000; Sanger et al., 2001; Tinassi et al., 1999). In one nonhuman primate model designed to test the sensorimotor learning hypothesis, owl monkeys performed attended, repetitive hand opening and closing $(1.5 \mathrm{~h} / \mathrm{d})$ until they were unable to perform the task in a controlled way (simulating a target specific clinical hand dystonia) (Byl et al., $1996 \mathrm{c}$; 1997). Electrophysiological mapping revealed shrinkage of the somatosensory hand representation on the trained side, unusually large overlapping receptive fields bilaterally, and persistence of the same digital representations across broad columnar distances on the cortex bilaterally (Blake et al., 2002; Byl et al., 1996; 1997). Two of the primates did not work intensely and used the whole arm and the trunk rather than the hand alone to close the hand piece. These two monkeys did not develop a disorder in fine motor control (Byl et al., 1997). Magnetoencephalography studies of human subjects with FHd revealed similar somatosensory degradation (Bara-Jimenez et al., 1998; Chen \& Hallet, 1998; McKenzie et al., 2000). The authors reported abnormalities in the area of the somatosensory hand representation on the trained side (e.g., reduction of in the spread of the digits and the overall hand area on the affected compared with the unaffected side) and the sequential ordering of the digits (e.g., loss of sequential digital ordering from inferior to superior bilaterally).

No intervention strategy has been one-hundred percent effective for restoring normal motor control in all FHd patients. Although botulinum toxin injections or baclophen can decrease dystonic cramping (Brin et al., 1987; Ceballos-Baumann et al., 1995; Cole et al., 1995; Fahn et al., 1987; Karp et al., 1994; Pullman et al., 1996; Tsui et al., 1993;
Van Hilten et al., 2000), the medications do not improve somatosensory differentiation and rarely enable musicians to return to their previous high levels of performance. Conservative intervention strategies based on the principles of neuroplasticity, including constraint induced therapy (Candia et al., 1999), sensitivity training (Tubiana et al., 1998), kinematic training (Mai et al., 1994), conditioning techniques (Liversedge et al., 1955, 1960), immobilization (Priori et al., 2001), and comprehensive sensory discrimination training (Byl et al., $2000 \mathrm{c}$ ) are being explored as alternate intervention strategies.

Although all FHd patients complain of uncontrolled, involuntary movements, primarily when performing a specific task, the clinical presentation varies from patient to patient. For example, certain patients have trouble in performing a single target task and others have difficulty with a variety of tasks, including uncontrolled movements with the involved digits simply with contact of the glabrous palm or digits with any surface. Some patients complain of a "dullness or numbness", whereas others complain of "increased sensitivity or jumpiness" of the dystonic digits. Possibly such clinical differences are related to the underlying somatosensory degradation. If this variability in response were more clearly understood, then intervention and prevention strategies could be tailored to the individual and potentially be more effective. The present study contributes to this gap in understanding.

We hypothesized that if FHd represented a learned de-differentiation of the cortical somatosensory organization of the hand, then clinical problems in sensory processing and motor control should be measurable. We also hypothesized that variations in clinical performance and somatosensory evoked responses should differentiate between subjects with severe versus mild hand dystonia. 


\section{EXPEWMUNTAL}

\section{Subjects}

The subjects were recruited from the Peter Ostwald Health Progran for Performing Artists and the Physical Therapy Faculty Practice at the University of California, San Francisco (UCSF). Male and female subjects between 20 and 60 years of age were eligible to participate in the study. Each subject (1) had been diagnosed with a unilateral focal hand dystonia (FHd) based on an evaluation by a neurologist; (2) had demonstrated observable involuntary twisting movements of the digits and wrist when performing the target or similar tasks; (3) had normal reflexes and no evidence of a peripheral neuropathy or central nervous system pathology; (4) had a history of FHd for more than $6 \mathrm{mo}$; (5) worked in an occupation demanding repetitive use of the hands (e.g., computer use, card dealing, playing a musical instrument, writing, court reporting); and (6) had not received an injected or systemic drug to control the dystonia for more than 6 mo before admission to the study.

The subjects lived in the San Francisco Bay area or were willing to stay there for several days to complete the testing. From a previous database of healthy controls, two groups of healthy subjects were age and sex matched and then randomly selected as historic reference controls. The purpose and procedures of the study were explained to each subject, and signed consent was obtained before testing. The study was approved by the UCSF Committee on Human Research.

\section{Procedures}

A broad battery of standardized clinical tests were administered to each FHd subject $(n=17)$ and to all historic controls $(n=17)$. The test procedures and the reliability of testing described in prior studies are summarized in Table 1 (Byl et al., 1996 a-b; 2000 a-c; 2002). Specific subtests were summed into seven dependent variables:

1. physical musculoskeletal performance (selected range of motion, strength, neural tension);

2. sensory discrimination (graphesthesia, localization, kinesthesia, stereognosis)

3. fine motor efficiency (Purdue Test-time), fine motor skill (line tracing accuracy and time) and digital reaction time (averaged across the 5 digits for each hand);

4. motor control at the target task;

5. posture and balance;

6. functional independence; and

7. pain.

The subtests allowed for the comprehensive measurement of clinical performance. By combining the scores into seven dependent variables, we could control for the experimentwise error in the study. Low intercorrelations between each summated dependent variable $(r<0.1)$ suggested that the dependent variables were measuring a unique characteristic (Byl et al., 2000 a). All subjects with FHd were classified as having simple (dystonia limited to one target task) or dystonic dystonia (dystonic movements occurred with the target task, tasks similar to the target task, or surface contact of the hand). All subjects with FHd were first rated in terms of severity according to the Tubiana Dystonia Scale for Musicians (Tubiana et al., 1998):

$0=$ unable to do the target task;

$1=$ able to do limited aspects of the task or perform the task for very short periods;

$2=$ able to do the task with modification of technique;

$3=$ able to do the task but not efficiently or with normal quality).

Then, for purposes of correlational analysis, all subjects with FHd were classified into one of two 

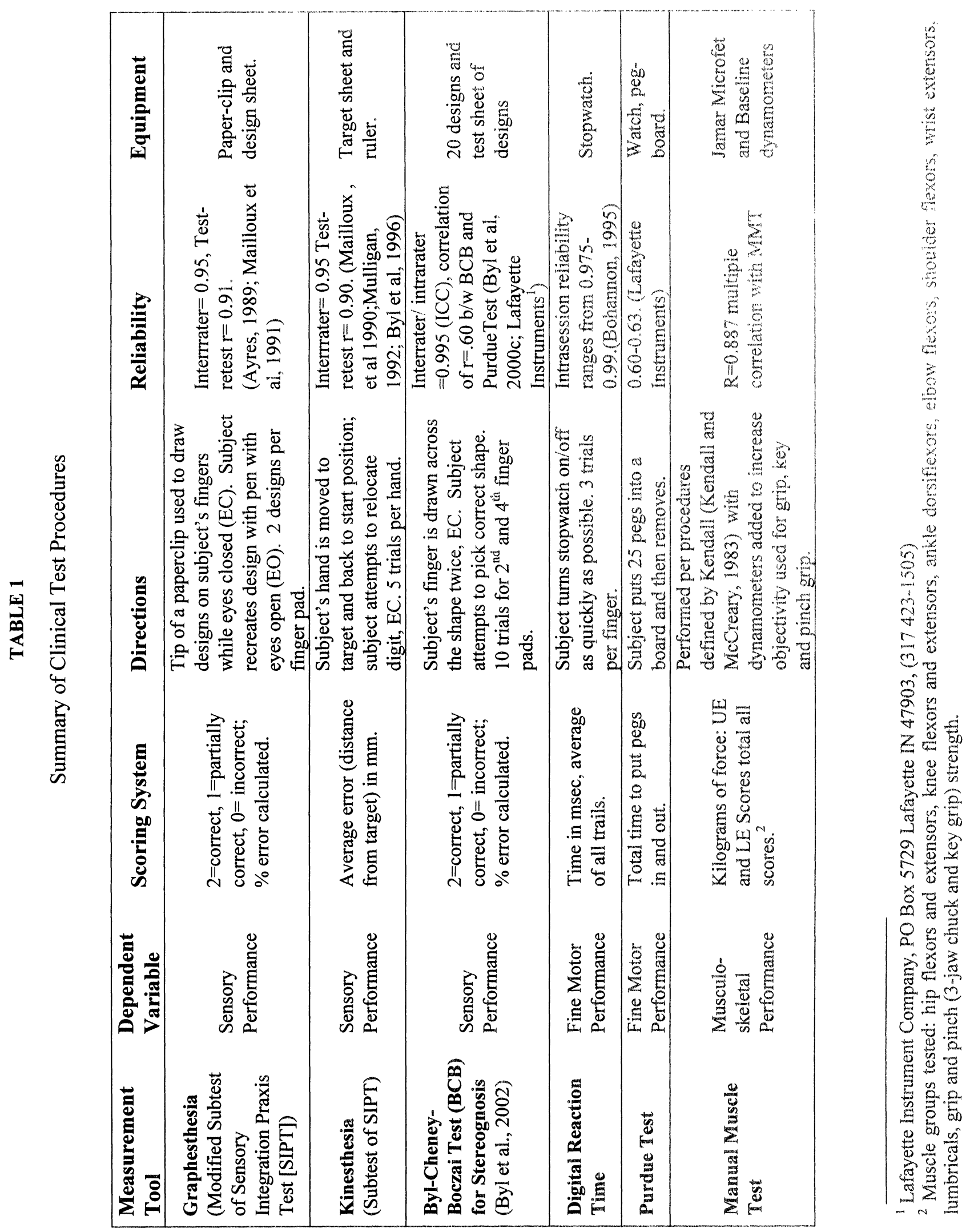


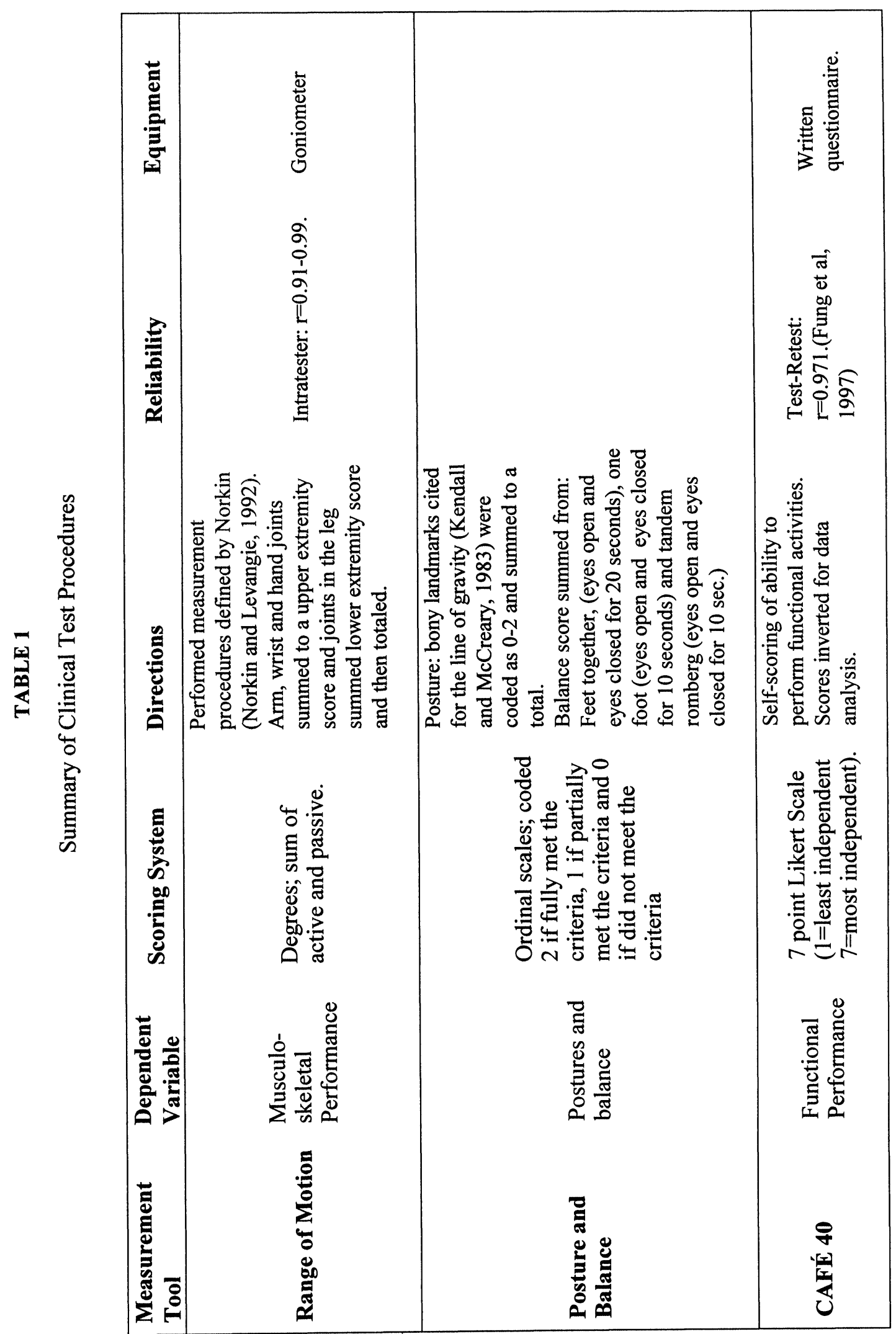


categories: mild or severe. Those with simple dystonia rated as 0 or 1 were classified as severe dystonia and those rated 2 or 3 as mild dystonia. All subjects with dystonic dystonia were rated as 0 or 1 and classified as severe dystonia.

Somatosensory testing was carried out according to standard protocols by trained research assistants. All testing in the Biomagnetic Imaging Laboratory at UCSF was performed by trained staff (Roberts et al., 1998; Rowley et al., 1995). The test-retest values for the magnetic source imaging testing established in this lab are high $(>0.9)$ (Spengler et al., 1997). A 37-channel biomagnetometer (Magnes II, 4D Neuroimaging, $1.5 \mathrm{fT}$, San Diego, California) placed in a magnetically shielded room with two circular sensors $(14.4 \mathrm{~cm})$ was used to create a magnetic source image of the hand. Two hundred and fifty air puffs were delivered within $1 \mathrm{~cm}^{2}$ sacs, for $30 \mathrm{msec}$, at 17 to 20 pounds psi, with a pseudorandom interstimulus interval 450 to $500 \mathrm{msec}$. The stimulus served as a super-threshold force designed to indent the skin 400 microns. Each digit was stimulated on the distal pad, middle and proximal segment on each digit on each hand. In addition, a similar stimulus was delivered to each side of the upper lip. Preliminary studies demonstrated that a psi of 15 was adequate to evoke a somatosensory field response, and that the latency and amplitude of this response were not significantly enhanced by a stimulus of 20 or 25 psi for normal subjects or for subjects with dystonia (See Fig. 1).

A normal somatosensory-evoked field response (SEF) elicited by the pneumatic cutaneous response is characterized by a peak amplitude at a latency between 30 and $70 \mathrm{msec}$, subject to a signal to noise ratio greater than 4 , goodness of fit (model/ data) $>0.95$, with a minimal confidence volume less than $3000 \mathrm{~mm}^{3}$ (Roberts, et al., 1998; Rowley et al., 1995). The dependent variables, recorded for each SEF response, included latency $(\mathrm{msec})$, root mean square (rms) amplitude across sensor channels
(fT), and location of the digits on the $\mathrm{x}, \mathrm{y}$, and $\mathrm{z}$ axes (cm). The following variables were determined: (1) amplitude of the SEF was integrated over time; (2) ratio of mean SEF amplitude to latency was calculated; (3) order of the digits on the $\mathrm{z}$ axis, plotted inferior to superior from D1 to D5; (4) spread of digits, calculated by subtracting the maximum centimeter distance between the most widely separated digits; and (5) volume of the digital representation, calculated based on the formula for an ellipsoid ( $4 / 3 \pi$ times the radius of the spread on $x, y$, and $z$ axes).

\section{Research design}

This was a descriptive study including three groups of subjects. All dependent variables were described by mean and standard deviation (SD). Line graphs and scatter plots were created for visual analysis of the relation of SEF amplitude across latency. Given the low correlation between the dependent variables, each dependent variable for each limb was considered independent. Thus, we tested each dependent variable for significance at $\mathrm{p} \leq 0.05$ (two-tailed). Where multiple subtests were combined or multiple trials were combined to create a dependent variable, the number of measurements was based on the number of subjects times the number of test components/ trials.

\section{Data analysis}

Based on the somatosensory and clinical dependent variables, we analyzed the differences between controls and FHd subjects and within subjects with FHd using the Student $t$ test or an analysis of variance (ANOVA) for the dependent variables measured with ratio data or the Wilcoxon Ranked Sum or Wilcoxon Two-Sample Test for the dependent variables measured on an ordinal scale The severity groupings for the FHd subjects were correlated with clinical performance parameters and 

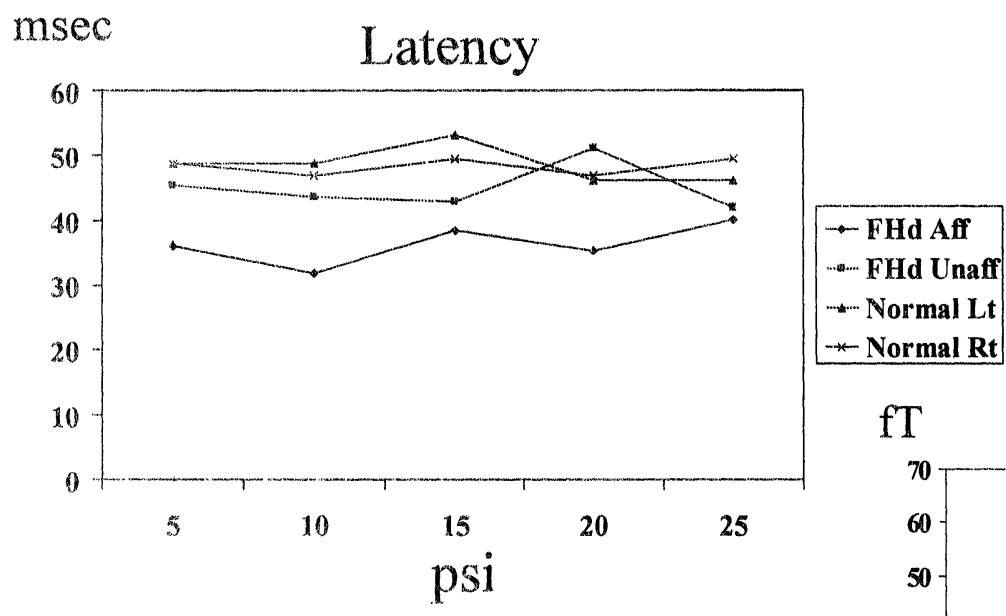

FIId $=$ two subjects, 3 trials, 3 digits

Normal =four subjects, 3 trials, 3 digits

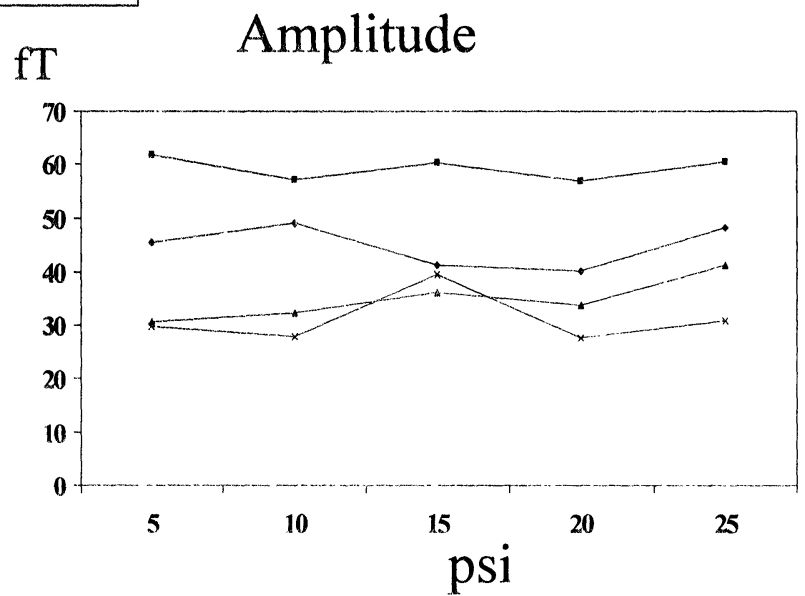

Fig. 1: Latency and amplitude of somatosensory evoked field response (SEF).by stimulus force. Controls and subjects with mild versus severe FHd. There were no consistent differences in the latency or the amplitude of the somatosensory evoked response between 5 and 20 psi for the healthy control subjects ( 4 subjects, 3 trials, 3 digits) or those with focal hand dystonia (2 subjects, 3 trials, 3 digits). The amplitude did increase slightly when the stimulus force was increased to $25 \mathrm{psi}$.

somatosensory variables, with mild dystonia coded as 1 and severe hand dystonia coded as 2 in the correlation matrices. The correlations were tested for significance using the Z-test for Correlation Coefficients based on preliminary studies, with an effect size of 1.0 , alpha at .05 and beta at .20 , a total of 15 subjects was needed to achieve a power of $80 \%$ for finding a significant difference.

\section{RESULTS}

There were 9 males and 8 females with FHd between the ages of 23 and 55 years [with a mean of $39.9 \pm 11.1$ years). All worked in jobs requiring repetitive hand movements. Ten were musicians. Eleven of the FHd subjects had simple dystonia and six had dystonic dystonia. Ten subjects could no longer practically perform the task and were classified with severe dysonia and seven could perform the task for short periods of time with modification of technique and were classified with mild dystonia (Table 2). The 15 subjects in the control group for somatosensory measurements ranged in age from 23 to 57 years with a mean age of 37.4 years $( \pm 9.7$ years). There were 8 males and 7 females. Two were musicians and the other subjects worked in jobs requiring repetitive hand use on a computer keyboard (Table 3). Of the 17 reference controls selected for comparing clinical 
TABLE 2

Description of subjects with focal hand dystonia

\begin{tabular}{|c|c|c|c|c|c|c|c|}
\hline Age & Gender & $\begin{array}{c}\text { Hand } \\
\text { Dominance }\end{array}$ & Occupation & $\begin{array}{c}\text { Type of } \\
\text { Dystonia }\end{array}$ & Severity $^{2}$ & $\begin{array}{l}\text { Involved } \\
\text { Side/Digits }\end{array}$ & $\begin{array}{c}\text { Wrist } \\
\text { Flex/Ext }\end{array}$ \\
\hline 22 & $\mathrm{~F}$ & $\mathrm{R}$ & Musician flute & Simple & 1 & $23-5$ & No \\
\hline 26 & M & $\mathrm{R}$ & Musician bagpipe & Simple & 2 & $L .3-5$ & No \\
\hline 28 & M & $\mathrm{R}$ & Musician-guitar & Simple & 1 & $\mathrm{R} 2$ & No \\
\hline 29 & $\mathrm{~F}$ & $\mathrm{R}$ & Computer Programmer & Simple & 0 & LI-5 & No \\
\hline 36 & M & $\mathrm{R}$ & Card Dealer & Simple & 2 & RI-2 & No \\
\hline 30 & $\mathrm{~F}$ & $\mathrm{R}$ & Musician- violin & Simple & 2 & $4.2-5$ & No \\
\hline 41 & M & $\mathrm{R}$ & Physician & Dystonic & 1 & R $1-2$ & Yes \\
\hline 37 & $\mathrm{~F}$ & $\mathrm{R}$ & Musician-flute & Simple & 1 & $L 4-5$ & No \\
\hline 50 & $\mathrm{M}$ & $\mathrm{R}$ & Musician" saxophone & Dystonic & 0 & $\begin{array}{l}\text { L } 1.5 \\
\text { RI }-5 * \\
\end{array}$ & Yes \\
\hline 50 & $\mathrm{~F}$ & $\mathrm{R}$ & Word Processing."Computer & Dystonic & 0 & $L 1-5$ & Yes \\
\hline 44 & M & $\mathrm{R}$ & $\begin{array}{l}\text { Administrator-High } \\
\text { computer use }\end{array}$ & Simple & 2 & RLI-3 & Yes \\
\hline 52 & M & $\mathrm{R}$ & Pianist-Band Leader & Simple & 2 & $\mathrm{R} 2-5$ & Yes \\
\hline 35 & $\mathrm{~F}$ & $\mathrm{R}$ & Pianist-composer & Simple & 2 & R1-5 & Yes \\
\hline 45 & M & $\mathrm{L}$ & Musician-oboe & Simple & 2 & $1.3-5$ & No \\
\hline 44 & M & $\mathrm{R}$ & Guitarist-Programmer & Dystonic & 1 & R. $1-5$ & No \\
\hline 45 & $\mathrm{~F}$ & L & Musician-piano & Dystonic & 1 & $R 1 \ldots 5$ & Yes \\
\hline 65 & $\mathrm{~F}$ & $\mathrm{R}$ & Word Processor & Dystonic & 1 & $\mathrm{R} 4 m 5$ & No \\
\hline
\end{tabular}

The focal hand dystonia subjects comprised 9 males and 8 females between the ages of 23 and 55 years (mean 39.9 years). Eleven of the FHd subjects were classified as having simple dystonia and six with dystonic dystonia. Ten were classified as having severe dystonia (rated 0.1 on the Tubiana Scale). Ten were musicians, one $\left(^{*}\right)$ previously diagnosed with FHd on the opposite side.

\section{${ }^{1}$ Type of Dystonia:}

Simple: movement dysfunction only on one target task Dystonic: movement dysfunction on a variety of similar tasks

\section{${ }^{2}$ Severity of target specific dystonia:}

0 unable to do the target task;

1 able to do limited aspects of the task or perform the task for very short periods;

2 able to do the task with modification of technique;

3 able to do the task but not efficiently or with normal quality (105) 
TABLE 3

Description of healthy control subjects

\begin{tabular}{|c|c|c|l|l|}
\hline Age & Gender & $\begin{array}{c}\text { Hand } \\
\text { Dominance }\end{array}$ & Repetitive hand use & Occupation \\
\hline 22 & F & R & High level of computer use and manual therapy & Graduate Student \\
\hline 28 & M & R & High level of computer use and manual therapy & Graduate Student \\
\hline 28 & M & R & High level of computer use and manual therapy & Graduate Student \\
\hline 28 & F & R & High levels of computer use -Data analysis & Graduate Student \\
\hline 32 & M & R & High levels of computer use-Data analysis & PhD Researcher \\
\hline 35 & F & R & High repetitive hand use on Musical instrument & Musician \\
\hline 38 & M & R & High level of computer use-data analysis & PhD Researcher \\
\hline 40 & F & R & High levels of computer use-data analysis & Post Doc Researcher \\
\hline 50 & M & R & High levels of computer use & Administrator \\
\hline 50 & F & R & High repetitive hand use on musical instrument & Musician \\
\hline 30 & M & R & High levels of writing & Graduate student \\
\hline 30 & F & R & High levels of writing & Graduate student \\
\hline 50 & M & R & High level of computer use-data analysis & Research Scientist \\
\hline 42 & M & R & High levels of computer use & Business administrator \\
\hline 58 & F & R & High level of computer use & Educator \\
\hline
\end{tabular}

The control group comprised 7 females and 8 males between the ages of 22 and 58 years (mean age 37.4 years). All healthy control subjects were involved in jobs demanding high levels of repetition; two were musicians.

performance, there were 5 males and 12 females with an average age of 30.2 years ( \pm 3.6 years). The majority of control subjects who volunteered for the clinical measurements were graduate students, faculty, or friends of students or faculty who had a history of repetitive hand use (e.g. intensive note taking and computer use).
Table 4 summarizes the results of the clinical performance parameters for patients with FHd and healthy controls. Compared with healthy controls, patients with FHd performed significantly worse when using either the affected or unaffected side in terms of musculoskeletal skills, fine motor control, and sensory discrimination. Scores for posture and 


\section{TABLE 4}

Clinical performance of controls and FHd subjects by severity of dystonia ${ }^{1,2,3}$

\begin{tabular}{|c|c|c|c|c|c|c|c|c|}
\hline \multirow[b]{2}{*}{$\begin{array}{l}\text { Dependent } \\
\text { Variables }\end{array}$} & \multirow{2}{*}{$\begin{array}{c}\text { No. } \\
\text { subtest } \\
\text { s }\end{array}$} & \multirow[b]{2}{*}{ Range } & \multicolumn{2}{|c|}{ Affected Side FHd } & \multicolumn{4}{|c|}{ Unaffected Side FHd } \\
\hline & & & $\begin{array}{l}\text { Severe } \\
n=10\end{array}$ & $\begin{array}{l}\text { Mild } \\
\mathrm{n}=7\end{array}$ & $\begin{array}{l}\text { Severe } \\
\mathrm{n}=10\end{array}$ & $\begin{array}{l}\text { Mild } \\
\mathrm{n}=7\end{array}$ & Right & Left \\
\hline $\begin{array}{l}\text { Physical } \\
\text { performance }\end{array}$ & 4 & $30-350$ & $235.9(36.6) * 7$ & $261.0(35.8) * 7$ & $273.7(32.5)$ & $275.7(42.3)$ & $\begin{array}{l}295.1 * 1 \\
(25.1)\end{array}$ & $\begin{array}{c}289.4 * 2 \\
(24.2)\end{array}$ \\
\hline Balance/Posture & 2 & $0-100$ & $87.1(12.2)$ & $90.9(4.5)$ & $87.1(12.2)$ & $90.9(4.5)$ & $\begin{array}{l}96 \\
(3 .\end{array}$ & $\begin{array}{l}6 \\
6)\end{array}$ \\
\hline Fine Motor Skills & 6 & $70-450$ & $189.4(34.4)$ & $198.1(5.2)$ & $186.7(48.2)$ & $191.4(42.3)$ & $\begin{array}{l}139.0 * 3 \\
(25.5)\end{array}$ & $\begin{array}{c}139.0 * 4 \\
(25.6)\end{array}$ \\
\hline $\begin{array}{l}\text { Task Specific } \\
\text { Motor Control }\end{array}$ & 1 & $0-100$ & $49.0(12.7) * 8$ & $59.5(5.4) * 8$ & $89.5(8.0) * 9$ & $64.6(9.9) * 9$ & $\mathrm{~N}$ & $A$ \\
\hline Sensory Skills & 6 & $30-380$ & $276.3(67.0)+$ & $274.8(12.9)+$ & $211.8(65.9)$ & $231.8(66.1)$ & \begin{tabular}{|l|}
$175.0 * 5$ \\
$(29.6)$ \\
\end{tabular} & $\begin{array}{c}172.1 * 6 \\
(16.5) \\
\end{array}$ \\
\hline Independence & 2 & $0-100$ & $91.7(5.98)$ & $93.5(4.8)$ & $91.7(5.98)$ & $93.5(4.8)$ & $\begin{array}{l}91 \\
(5 .\end{array}$ & $\begin{array}{l}9 \\
6)\end{array}$ \\
\hline Pain & 2 & $0-100$ & $88.7(9.5)$ & $96.4(5.0)$ & $99.0(3.2)$ & $100.0(0)$ & $\begin{array}{l}97.2 \\
(6.8)\end{array}$ & $\begin{array}{l}97.4 \\
(6.1)\end{array}$ \\
\hline
\end{tabular}

The clinical tests were summed to measure seven clinical dependent variables. The clinical performance scores were significantly lower for FHd subjects compared with control subjects. Compared with those with severe focal hand dystonia, FHd subjects with mild dystonia demonstrated better physical performance, were slower but more accurate in sensory and fine motor performance, and demonstrated bilateral problems with task specific motor control.

${ }^{1}$ FHD $(n=17)$ Controls $(n=17)$

${ }^{2}$ Differences between Controls and FHd Subjects (combined across groups):

${ }^{3}$ Differences between those with mild and severe dystonia

\section{Critical Values:}

$$
\begin{array}{lll}
* 1, \mathrm{t}=4.6(\mathrm{p}<0.001) ; & * 4, \mathrm{t}=13.6(\mathrm{p}<0.001) ; & * 7 \mathrm{t}=4.50 ; \mathrm{p}<0.001 ; \\
* 2, \mathrm{t}=3.12(\mathrm{p}<0.002) & * 5, \mathrm{t}=8.66(\mathrm{p}<0.001) & * 8 \mathrm{t}=3.09 ; \mathrm{p}<0.01 ; \\
* 3 ; \mathrm{t}=6.09(\mathrm{p}<0.001) ;{ }^{*} & * 6, \mathrm{t}=8.87 ;(\mathrm{p}<0.001) ; & * 9 \mathrm{t}=8.00 ; \mathrm{p}<0.0001
\end{array}
$$

+ Although the total sensory score was not significantly different, there was a significant difference in the subtests in terms of time for sensory processing (87.4 (53.8) for those with severe dystonia compared with $125.2(68.9)$ for those with mild dystonia $(\mathrm{t}=2.04 ; \mathrm{p}<0.05)$ and accuracy $50.4(26.1)$ for those with severe dystonia compared with $26.1(27.0)$ for those with mild dystonia ( $\mathrm{t}=2.22 ; \mathrm{p}<0.05)$

\section{Definitions:}

Severe Dystonia: included Dystonic Dystonia (0-3) Simple (0-1)

Mild Dystonia: Simple Dystonia- 2-3

\section{Scale Scores:}

Physical performance, balance/posture, independence, pain = high scores are good

Motor skills and sensory skills = low scores are good 
balance were lower for FHd subjects than controls, but the differences were not significant. There were no differences between the groups in terms of pain or functional independence. On the affected limb, those with severe dystonia had reduced performance measurements in musculoskeletal skills and target specific motor control compared with those with mild dystonia. Although the overall sensory discrimination accuracy was low for all FHd subjects (with no significant differences by severity), for tasks that included speed and accuracy, those with severe dystonia performed the tasks faster than those with mild dystonia. On the unaffected side, those with mild dystonia demonstrated greater inaccuracy when performing the target specific task.

There were no significant differences between mean SEF latency or mean SEF amplitude for FHd subjects and reference controls, but the location of the digits on the $\mathrm{x}$ (bilateral) and $\mathrm{y}$ axes (affected) were significantly different $(\mathrm{p}<0.0001$, respectively) and the ratio of SEF mean amplitude to latency was higher for FHd subjects compared with the controls $(p \leq 0.05)$. On the unaffected side, the volume of the hand representation was significantly larger for FHd subjects than for controls $(\mathrm{p}<0.05)$ (see Table 5$)$.

TABLE 5

Differences in somatosensory responses for controls and subjects with $\mathrm{FHd}^{1}$

\begin{tabular}{|l|l|l|l|c|}
\hline & \multicolumn{2}{|c|}{ Affected Side } & \multicolumn{2}{c|}{ Unaffected Side } \\
\hline & Controls & Subjects & Controls & Subjects \\
\hline Latency (msec) & $45.9(7.4)$ & $43.6(4.0)$ & $45.1(7.8)$ & $44.1(4.3)$ \\
\hline Amplitude (Ft) & $45.2(20.6)$ & $54.4(12.1)$ & $48.7(18.8)$ & $46.7(7.4)$ \\
\hline $\begin{array}{l}\text { Ratio (Amplitude } \\
\text { to Latency) }\end{array}$ & $1.08(0.6) * 4$ & $1.36(0.7)^{*} 4$ & $1.20(0.6)$ & $1.31(0.8)$ \\
\hline Location (cm) & & & & \\
\hline Axis x & $1.25(0.3)^{*} 1$ & $1.7(0.3)^{*} 1$ & $1.21(0.2)^{*} 2$ & $2.00(0.4)^{*} 2$ \\
\hline Axis y & $3.84(0.5)^{*} 3$ & $4.3(0.3)^{*} 3$ & $3.95(0.3)$ & $3.90(0.2)$ \\
\hline Axis z & $9.32(0.3)$ & $9.5(0.9)$ & $9.58(0.3)$ & $9.50(0.4)$ \\
\hline Spread $\left(\mathrm{cm}^{*}\right)$ & & & & \\
\hline Axis x & $0.63(0.2)$ & $1.0(0.4)$ & $0.60(0.3)$ & $0.84(0.4)$ \\
\hline Axis y & $1.04(0.4)$ & $1.3(0.8)$ & $0.91(0.5)$ & $1.07(0.5)$ \\
\hline Axis z & $0.94(0.4)$ & $1.1(0.4)$ & $0.89(0.3)$ & $1.10(0.5)$ \\
\hline Volume $\left(\mathrm{cm}^{3}\right)$ & $0.39(0.2)$ & $0.58(0.5)$ & $0.26(0.3)^{*} 5$ & $0.67(0.6)^{* 5}$ \\
\hline
\end{tabular}

As measured by magnetoencephalography, there were no significant differences in the mean amplitude and latency of the somatosensory evoked field responses for controls and those with FHd. However, compared with controls, the FHd subjects had a higher ratio of the mean amplitude to mean latency on the affected side, there was a significant difference in location of the digits on the $x$ and $y$ axes, and the area of the hand representation was significantly greater on the unaffected side.

'Controls: $\mathrm{n}=15$; Subjects: $\mathrm{n}=17$

*significant $\mathrm{t}_{1}=7.62 ; \mathrm{p}<0.0001 ; \mathrm{t}_{2}=7.60 ; \mathrm{p}<0.0001 ; \mathrm{t}_{3}=5.93 ; \mathrm{p}<0.0001 ; \mathrm{t}_{4}=2.05 ; \mathrm{p}<0.05 ; \mathrm{t}_{5}=2.12 ; \mathrm{p}<0.05$ 
TABLE 6

Somatosensory evoked field response by severity of dystonia: digit spread by axes and volume

\begin{tabular}{|l|l|l|l|l|}
\hline \multirow{2}{*}{ Spread of digits } & \multicolumn{2}{|c|}{ Affected Side } & \multicolumn{2}{c|}{ Unaffected Side } \\
\cline { 2 - 5 } & Controls & Subjects & Controls & Subjects \\
\hline Axis x & $1.05(0.61)$ & $0.82(0.31)$ & $1.18(0.56)$ & $0.822(0.30)$ \\
\hline Axis y & $1.32(0.67)$ & $1.01(0.52)$ & $1.08(0.57)$ & $0.761(0.32)$ \\
\hline Axis z & $0.81(0.98)$ & $0.90(0.42)$ & $1.11(0.41)$ & $0.782(0.52)$ \\
\hline Volume $\left(\mathrm{cm}^{3}\right)$ & $0.71(0.69) * 1$ & $0.45(0.38) * 1$ & $0.82(0.76) * 2$ & $0.524(0.52) * 2$ \\
\hline
\end{tabular}

$*_{1} \mathrm{t}=2.15(<0.05) ; *^{*} \mathrm{t}=2.00(<0.05)$

On both the affected and unaffected side, the volume of the representation of the hand was significantly larger for those with mild compared with those with severe hand dystonia.

Table 6 summarizes the parameters of the somatosensory evoked field responses (SEFs) for those with mild versus severe dystonia. Bilaterally, for those with mild dystonia, the volume of the representation of the hand was significantly larger than in those with severe dystonia.

Figure 2 illustrates the different patterns of the somatosensory evoked field responses (SEFs) for the digits for one control and two subjects with FHd. The patterns of the SEFs for controls and those with FHd were similar on the lip (uninvolved body part), but the SEF patterns for the digits were different for healthy controls when compared with those of subjects with FHd. The pattern of the SEF for the control subject (A and D) was characterized with a primary burst of activity at $40 \mathrm{msec}$ at an amplitude between 70 and $100 \mathrm{fT}$, quieting at 120 msec. For the subject with severe dystonia (B and E) on both sides, the first burst of activity was $<$ (at) $40 \mathrm{msec}$ with an amplitude of $>150 \mathrm{fT}$ and either a second burst of activity or continued activity (60 fT) after $120 \mathrm{msec}$. On the unaffected side for the subject with mild dystonia, the $\operatorname{SEF}(C)$ had the first burst of activity at $30 \mathrm{msec}$ (amplitude of $>150 \mathrm{fT}$ ) with continued firing at an amplitude of $70 \mathrm{fT}$ even at $120 \mathrm{msec}$. On the affected side (F), the activity appeared poorly organized with the most activity at $80 \mathrm{msec}(60 \mathrm{fT})$ with continued activity beyond $120 \mathrm{msec}$.

The distribution of amplitude by latency for the somatosensory evoked field responses for FHd subjects and controls is presented in Fig. 3. When amplitude was integrated across the somatosensory evoked field response time, the amplitude was significantly higher for controls compared with FHd subjects on the affected side, affected digits (A, Fig. 3) but not unaffected digits (B, Fig. 3). On the unaffected side (digits matched to the dystonic digits), however, the amplitude of the somatosensory evoked field response was significantly greater for FHd subjects than for controls (C, Fig. 3).

The scatter plots in Fig. 4 illustrate the distribution of SEF amplitude by latency (by side) for control and FHd subjects. For the FHd subjects, the distribution of amplitude by latency was not linear on the affected side. On scatter plot A, there was a 

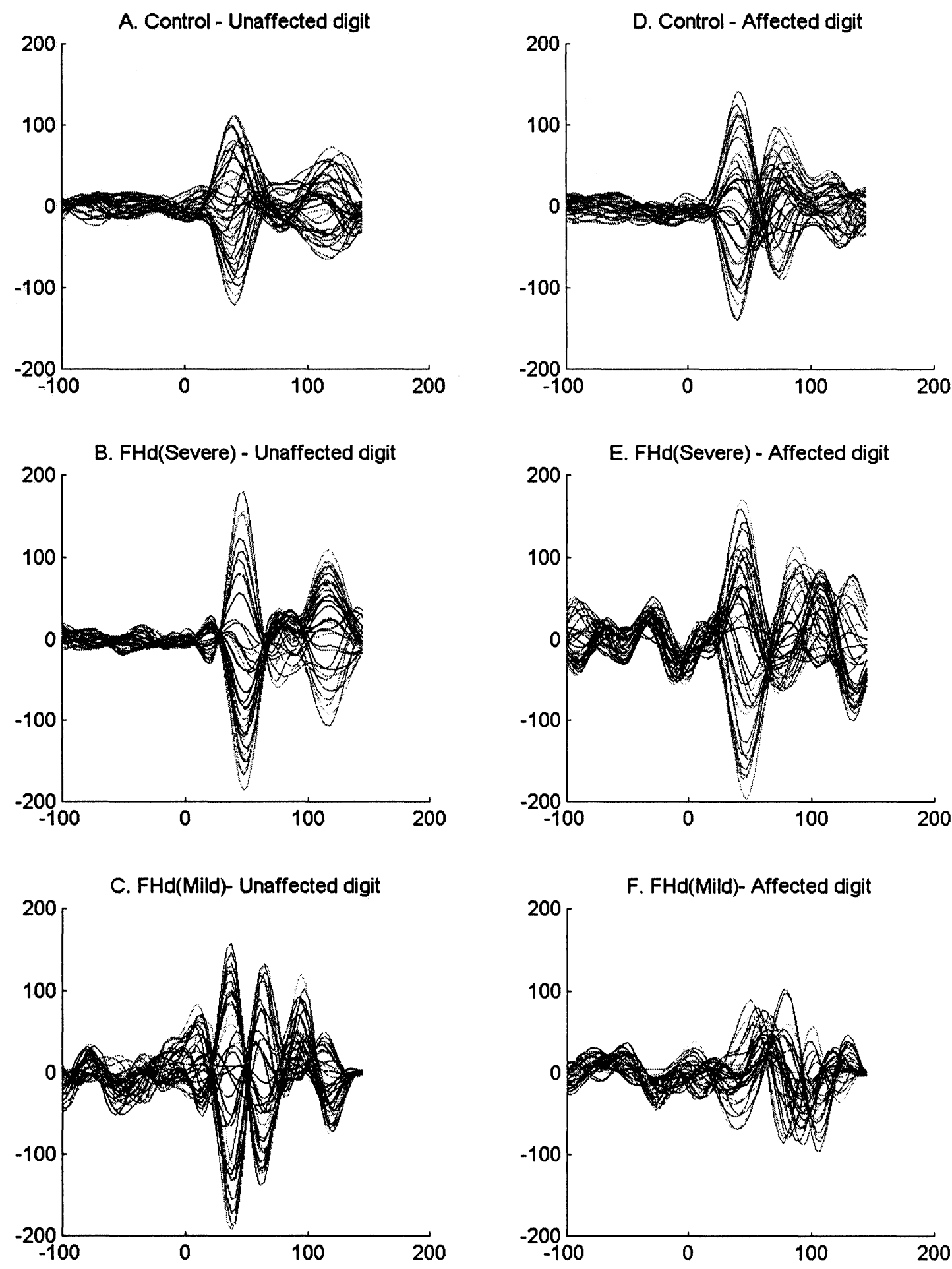

Fig. 2: A visual representation of the differences in amplitude and volume over time for FHd subjects and controls 
A

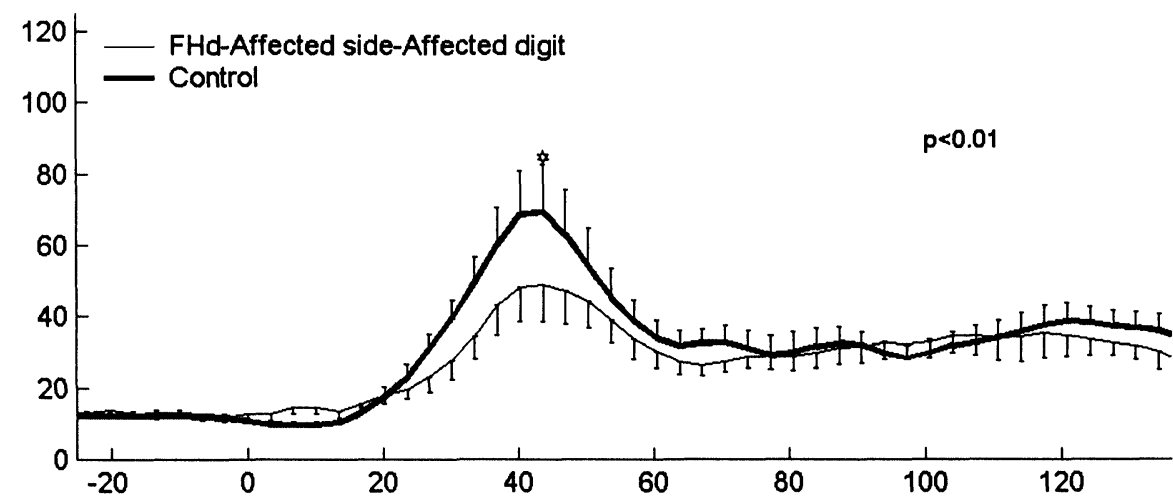

B

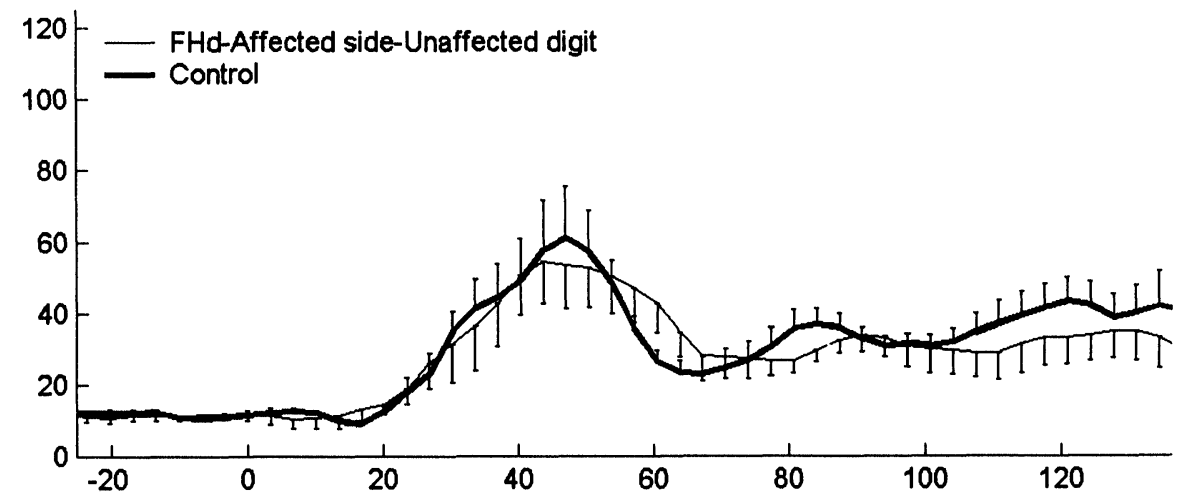

C

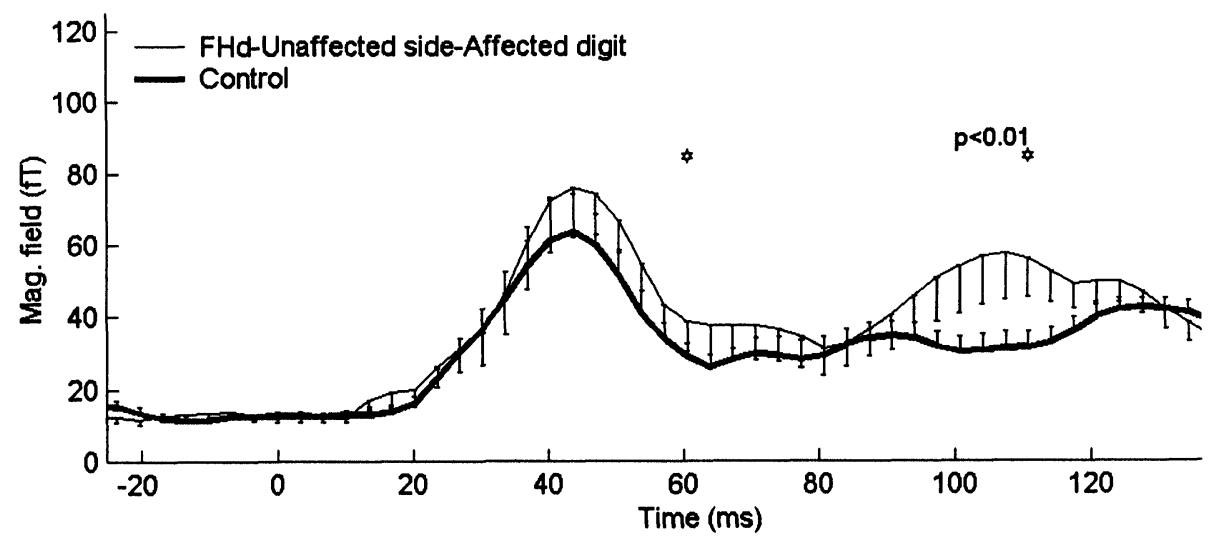

Fig. 3: Somatosensory evoked field responses: amplitude integrated by latency for FHd and control subjects. 

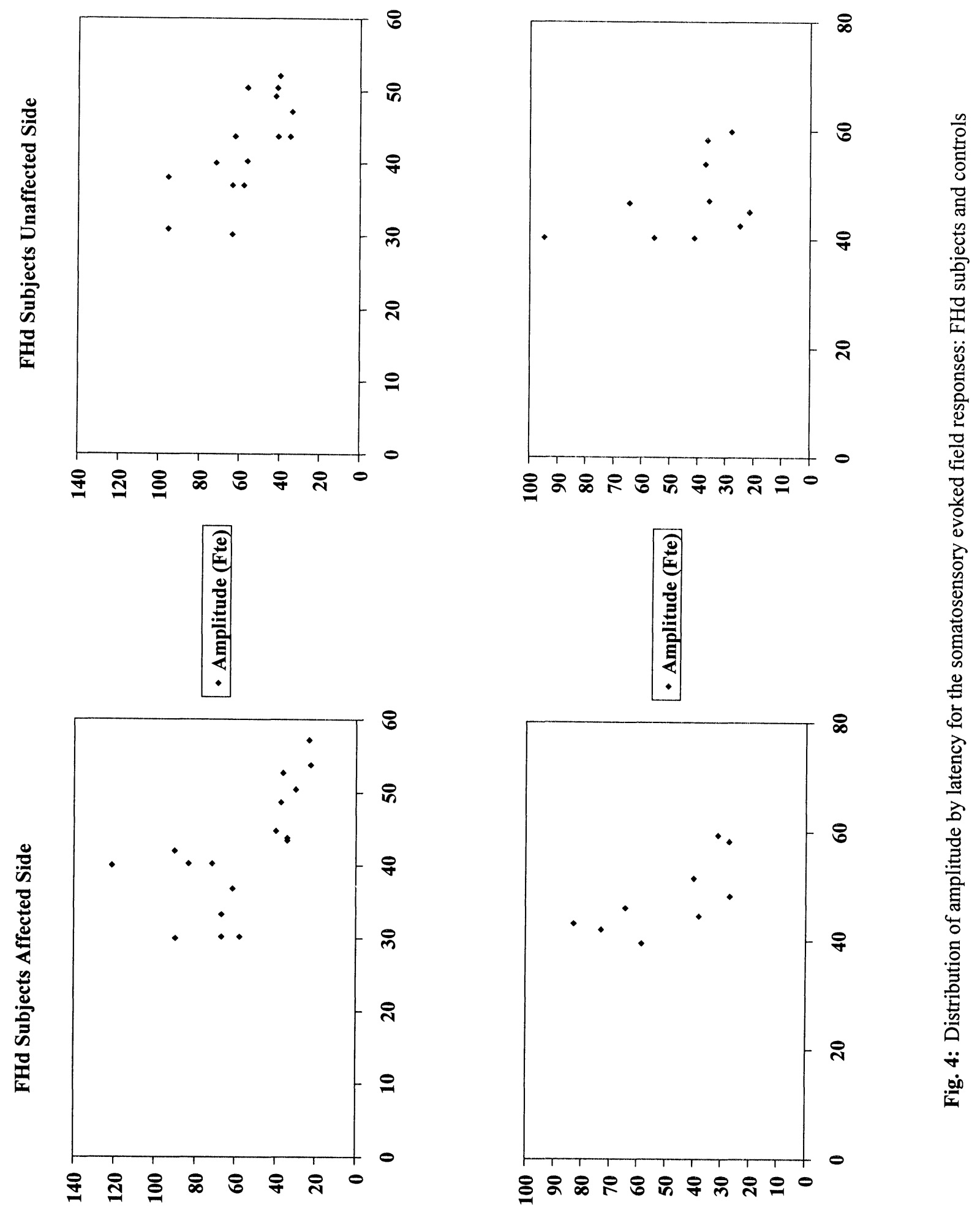
A

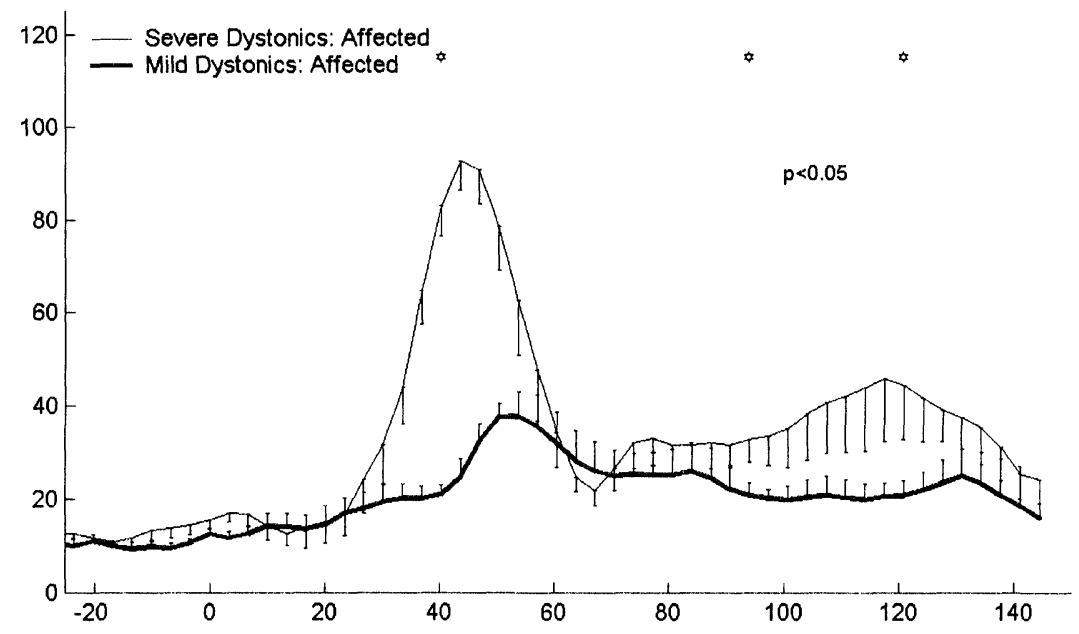

B

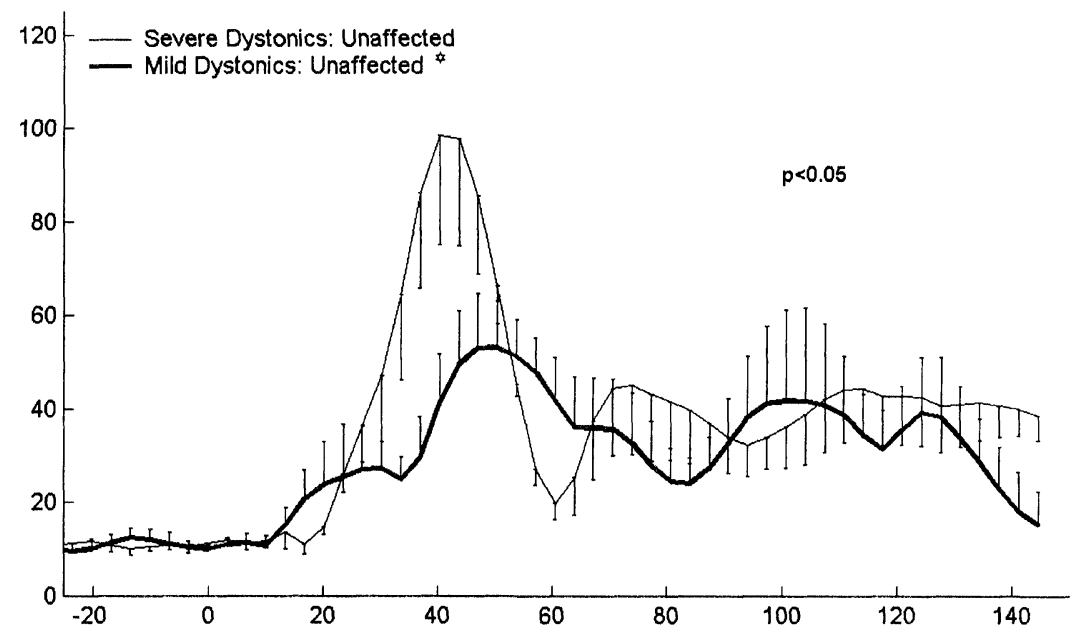

Fig. 5 Somatosensory evoked field responses: Amplitude integrated by latency for FHd subjects (severe versus mild dystonia).

bimodal distribution of mean SEF amplitude plotted by mean latency (mean latency ranging from 30 to 60 milliseconds and the mean amplitude ranging from 20 to $119 \mathrm{fT}$ ). There was a negative linear trend of amplitude by latency for the digits on the unaffected side for FHd subjects and controls $(\mathrm{B}, \mathrm{C})$; as the latency increased, the amplitude decreased. Figure 5 provides a visual representation of the differences in amplitude integrated by latency for those with severe versus mild dystonia. For subjects with focal hand dystonia, on the affected side, the amplitude of the somatosensory evoked field response was significantly lower for those with mild dystonia. 


\section{TABLE 7}

Somatosensory evoked field responses (SEF): correlation of the ratio of amplitude to latency with severity of FHd and clinical performance criteria

\begin{tabular}{|c|c|c|c|c|}
\hline \multirow{2}{*}{ Dependent Variables } & \multicolumn{2}{|c|}{ Affected Side } & \multicolumn{2}{|c|}{ Unaffected Side } \\
\hline & SEF Ratio & Severity of FHd & SEF Ratio & Severity of FHd \\
\hline Physical Performance & $-0.3910 * 1$ & $-0.3755 * 2$ & -0.1071 & $-0.401 * 3$ \\
\hline Fine Motor Skills & $-0.4670 * 4$ & -0.1076 & -0.1667 & -0.1851 \\
\hline Motor Control Target Task & $-0.6116 * 5$ & $-0.5881 * 6$ & $-0.7867 * 7$ & $0.7929 * 8$ \\
\hline Sensory Skills & -0.28271 & -0.0062 & -0.1077 & -0.0402 \\
\hline Pain & -0.19841 & -0.3896 & -0.2090 & -0.0190 \\
\hline & \multicolumn{2}{|c|}{ SEF Ratio } & \multicolumn{2}{|c|}{ Severity of FHd } \\
\hline Posture/Balance $(n=34)$ & \multicolumn{2}{|c|}{-0.2911} & \multicolumn{2}{|c|}{-0.362} \\
\hline Independence $(n=17)$ & \multicolumn{2}{|c|}{-0.1425} & \multicolumn{2}{|c|}{-0.328} \\
\hline
\end{tabular}

Note: Correlated with severe dystonia coded as " 2 " and mild dystonia coded as " 1 "

$\begin{array}{ll}\text { Critical Values } & \\ * 1 \mathrm{z}=3.29 ; \mathrm{p}<0.0006^{*} & * 3 \mathrm{z}=3.53 ; \mathrm{p}<0.0004 \\ * 2 \mathrm{z}=3.31 ; \mathrm{p}<0.0005 & * 4 \mathrm{z}=3.67 ; \mathrm{p}<0.0004\end{array}$

$* 5 \mathrm{z}=2.38 ; \mathrm{p}<0.0094$

$* 6 \mathrm{z}=3.47 ; \mathrm{p}<0.0004$
$* 7 \mathrm{z}=3.02 ; \mathrm{p}<0.0013$

$* 8 \mathrm{z}=3.13 ; \mathrm{p}<0.001$ when compared with subjects with severe dystonia Such a discrepancy in amplitude across latency for those with mild compared with those with severe dystonia was also measured on the unaffected side.

The digits for the control subjects were orderly sequenced from inferior to superior on the $\mathrm{z}$ axis as expected. The digits of FHd subjects were not orderly (see Fig. 6). For example, on the affected side of the FHd subjects, the digits were all represented at the same location.

High, significant correlations $\left(0.9029_{\text {affected }}\right.$ and $0.8477_{\text {unaffected }} ; \mathrm{p}<0.001$ ) were found between dystonia severity and the ratio of SEF amplitude to latency, respectively (see Table 7). On the affected side, the SEF ratio and dystonia severity were significantly, negatively correlated (moderate to moderately high) with musculoskeletal performance and motor control on the target task; FHd subjects with mild dystonia and those with a low SEF ratio demonstrated higher performance than those with severe dystonia. There was also a significantly negative correlation between fine motor skills and the SEF ratio on the affected side; those with a high ratio of SEF amplitude to latency demonstrated greater inaccuracy. Similar to the affected side, on the unaffected side, there was a significant, moderately negative correlation between the severity of dystonia and musculoskeletal performance and a significantly negative correlation between the SEF ratio and motor control at the target task. However, on the unaffected side, there was a significant, positive correlation between the severity of dystonia and motor control on the target task; those with mild dystonia had lower scores on the target task than those with severe dystonia. 

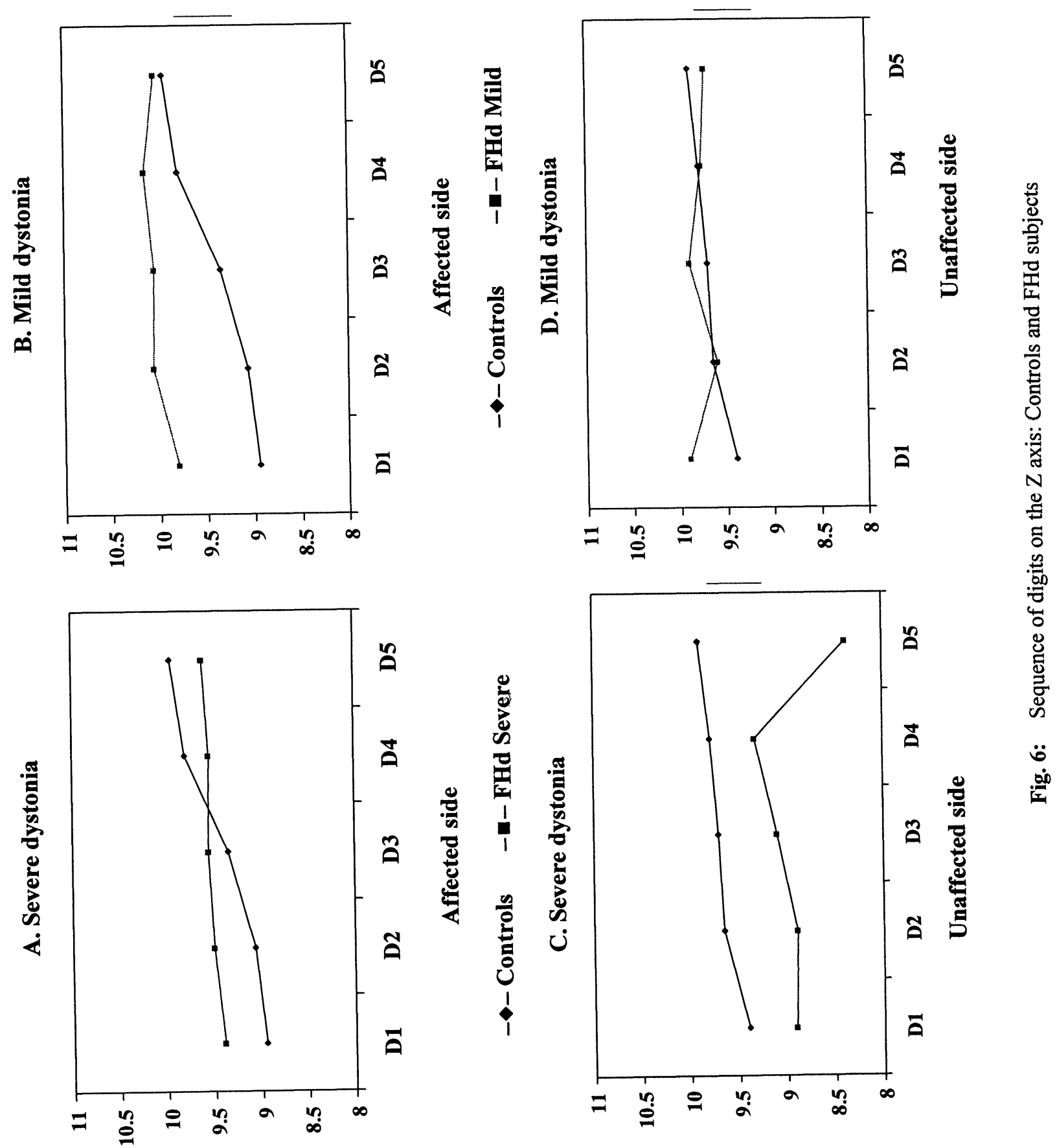


\section{DISCUSSION}

The findings from this study contribute new evidence supporting a strong relationship between clinical sensory and motor performance with somatosensory degradation in patients with FHd that distinguishes them from healthy controls and differentiates them by severity of dystonia. The results presented here are consistent with the proposed sensorimotor hypothesis of aberrant learning. The evidence also suggests, however, that FHd subjects do not present as a homogeneous group.

On the affected side, subjects with severe dystonia had more musculoskeletal limitations and more impaired task specific motor control compared with those with mild dystonia, with the SEP characterized by a short latency, high amplitude, and a reduced area of somatosensory hand representation.

Previous investigators have reported differences in somatosensory evoked responses in FHd subjects (digit clumping, loss of orderly digit sequencing, differences in the size of the area of the somato-sensory hand representation), but no significant difference in mean amplitude (BaraJimenez et al., 2000; Byl et al., 1996 a-c; Elbert et al., 1998; Juliano et al., 1991). The findings from the current study indicate that the SEF patterns in those with severe dystonia and those with mild dystonia are complementary. Thus, when amplitude and latency are averaged across all subjects, the differences are cancelled.

The SEF ratio of amplitude and latency could be viewed as a neural slew factor, projecting a linear relation between the clinical severity of FHd and the severity of somatosensory degradation. A high neural slew factor is consistent with a high gain in the sensorimotor feedback loop, whereas a low neural slew factor is consistent with a low gain in the sensorimotor feedback loop (Sanger \& Merzenich, 2000). Such feedback errors could explain the differences noted between the groups in terms of clinical performance. Although previous investigators (Bara-Jimenez et al., 2000; Byl et al., 1996 b-c; Sanger et al., 2000; Tinazzi et al., 1999), reported problems in sensory spatial discrimination in patients with FHd, information on clinical performance and somatosensory structure, as measured by magnetoencephalography, was not reported nor were clinical skills correlated by severity of dystonia. In the current study, subjects with focal dystonia demonstrated compromised clinical sensorimotor performance compared with controls with subjects with severe dystonia working faster but making more errors than those with mild dystonia.

Restrictions in musculoskeletal structure have been reported in patients with FHd (Wilson et al., 1991; Wilson et al. 1993; Lejinse, 1996). The current study confirms that subjects with FHd have restrictions in musculoskeletal performance when compared with controls, but the finding that subjects with severe dystonia had greater limitations in flexibility, strength, and neural tension than those with mild dystonia was totally unexpected. Many individuals with tight muscles and joint restrictions develop compensatory movements, but for such movements to resemble dystonia is unusual. Under conditions of stress and repetitive overuse, conceivably musculoskeletal limitations could increase the risk for developing dystonia (Wilson et al., 1991; 1993; Lejinse, 1996). Factors of causality would have to be confirmed by prospective, longitudinal, cohort studies documenting the occupational, physical, sensory, and fine motor characteristics of individuals who perform complex, repetitive hand tasks under stressful environmental or psychological conditions.

In the current study, for subjects with FHd, the fingers were not normally sequenced on the primary sensory cortex on either the affected or the unaffected side, and the size of the hand representation on the affected side was reduced in 
comparison with that on the unaffected side. The observation that the hand representation was reduced in those with severe dystonia would be consistent with a more serious degradation, including more extensive overlap of receptive fields across the columnar representation of the digits on the cortex. Compared with healthy controls, the size of the area of the hand representation for those with FHd was not significantly different on the affected side; on the unaffected side, however, the area of representation was larger for FHd subjects than for controls. This finding might represent an artifact of the study samples. Compared with control subjects, more FHd subjects were musicians $(58.8 \%$ versus $17.8 \%)$. Musicians reportedly have a larger somatosensory hand representation as a result of complex, repetitive hand use (Elbert et al., 1998). In Elbert's study of violinists, the representation for the left hand (used for complex fingering) was larger than that for the bowing hand. Even though computer keyboard users use their hands intensely, computer keyboarding does not necessitate the same complex movements that are required to play a musical instrument. For example, when playing advanced music on the piano, both hands and multiple digits must play simultaneously and individually with the arms moving concurrently to cover the length of the keyboard. Although some paired digital movements are required on the computer keyboard (e.g. the use of the shift or function key with a letter or number key), most frequently the user depresses one finger at a time. If computer users are applying stress-free hand strategies, then they can depress a single key using the intrinsic muscles (e.g. lumbricals and interossei instead of the long finger flexors) and then simply release the pressure down without requiring a reciprocal digital extension movement. In addition, they can use the mouse at a close distance, moving from the shoulder and elbow to position the mouse and then rotate the forearm to click instead of using rapid alternating digital movements to click the mouse.

The 'integration times' are primarily dictated by temporal requirements needed to recover from the inhibition that gates movement and dominates poststimulus excitability. With practice, possibly some individuals can improve performance until they exceed the limits of their integration time. Those who intensively use their hands should be encouraged to achieve precise sensory discrimination, to use intrinsic hand muscles and to avoid excessive overuse of the extrinsic flexors and extensors.

The sensorimotor learning hypothesis is consistent with the principles of neuroplasticity, the finite nature of neural adaptation, and the importance of accurate sensorimotor feedback for fine motor control (Byl et al., 1996; Sanger \& Merzenich, 2000). Neuroplasticity is also consistent with the hypothesis that FHd represents a case of aberrant learning. If $\mathrm{FHd}$ develops as a consequence of abnormal learning, then patients must first stop the repetition of the abnormal movement and then re-differentiate the somatosensory hand representation by performing attended, progressive, rewarded, sensorimotor behavioral activities (Juliano et al., 1991; Kaas et al., 1983; Merzenich et al., 1982; Merzenich et al., 1996 a-b; Nagarajan et al., 1997; Nakashima et al., 1989).

Our study has several limitations. The data were gathered from a small sample of patients with focal hand dystonia. Two different control groups were used to obtain somatosensory data and clinical performance. The stimulus (air puff) did not represent the minimum threshold stimulus for each individual subject. In the UCSF Biomagnetic Imaging Laboratory, a cutaneous stimulus of 17 to 20 pounds per square inch ( $\mathrm{psi}$ ) was considered an adequate stimulus to indent the skin 400 microns. This stimulus possibly represented a minimum stimulus for those whose evoked field response was characterized by a long latency and low amplitude but a maximum stimulus for those 
responding quickly with a short latency and high amplitude. Preliminary testing of the psi of the stimulus did not confirm this notion, however. An air puff of 15 psi was associated with an increase in amplitude over the 5 and 10 psi stimuli, both for healthy subjects and for patients with FHd, with little differences in the response characteristics at 20 and 25 psi. Minimal differences were found in latency measured between 5 and 25 psi stimuli levels. Thus, it is unlikely that this small force designed to indent the skin 400 microns could explain the consistent differences in somatosensory-evoked responses by severity.

The hypothesis of aberrant sensorimotor learning does not explain why some individuals who perform highly skilled, stereotypic, repetitive movements develop FHd and others do not. Issues of 'misuse' versus 'overuse' must be investigated. Possibly, initial, mild abnormal homuncular organization of the digits might result from genetic, congenital, or traumatic conditions. Such differences can be stable, however, until challenged by stress and or highly repetitive, stereotypic movements (Bara-Jimenez et al., 1998; Lejinse, 1999; Byl \& Topp, 1998). Teaching individuals how to use their hands in stress-free ways and how to maintain sensitive, precise, accurate sensorimotor processing could serve as an important foundation for the rehabilitation of patients with FHd. More studies are needed to determine if the same strategies could also be used to minimize the risk for developing occupationally related hand dystonia.

\section{Clinical implications}

The findings from this study have significant implications for rehabilitation. This study is the first clearly documenting a correlation between somatosensory degradation and clinical sensory and fine motor performance. It is also the first study noting that clinical performance and somato-sensory function are not homogeneous across all subjects with focal hand dystonia. These findings could represent aberrant learning within individuals who develop hand dystonia following a stressful history of repetitive overuse of the hand. Thus, theoretically, recovery of fine motor control must be based on the principles of neural adaptation. Logically, the intervention program must be designed to restore the somatosensory organization of the hand including the normalization of sensorimotor feedback. Individuals with severe FHd who demonstrate a high gain in the sensorimotor feedback loop might have to practice behaviors that raise the threshold of sensory excitability until voluntary fine motor outputs are controlled. Subjects with mild FHd demonstrating a low sensorimotor feedback loop gain might have to practice behaviors that lower the threshold of sensory excitability until voluntary fine motor outputs are normalized. All training must be progressive, without causing abnormal, involuntary, motor movements on the target and the related tasks.

\section{ACKNOWLEDGEMENT}

This research was supported in part by: University of California, San Francisco, School of Medicine, REAC Funds (nb), Faculty Development Award, Chapman University (am) NIH Grant: T01DC4855 (ssn).

\section{REFERENCES}

Allard T, Clark SA, Jenkins WM, Merzenich MM. 1991. Reorganization of somatosensory area 3b representations in adult owl monkeys after digit syndactyly. J Neurophysiol 66: 1048-1058.

Altenmueller E. 1998. Causes and cures of focal limb dystonia in musicians. In: Scott R, Black J. eds, Proc Intl Congress of Musicians: Health and the Musician (York, 1997). London, UK: Br Assoc Perf Art Medicine; G-1-1-12. 
Ayres AF. 1989. Sensory Integration and Praxis Tests (SIPT). Los Angeles, California, USA: Western Psychological Services.

Bara-Jiminez W, Catalan M, Hallett M. 1998. Abnormal somatosensory homunculus in dystonia of the hand. Ann Neurol 44: 828-831.

Bara-Jimenez W, Shelton P, Sanger TD, Hallett M. 2000. Sensory discrimination capabilities in patients with focal hand dystonia. Ann Neurol 47: 377-380.

Bell C. 1883. The Hand: Its Mechanism and Vital Endowments as Evincing Design. London, UK: William Pickering; 23.

Black KJ, Ongur D, Perlmutter JS. 1998. Putamen volume in idiopathic focal dystonia. Neurology 51: 819-824.

Blake DT, Byl NN, Cheung S, Bedenbaugh P, Nagarajan S, Lamb M, Merzenich M. 2002. Sensory representation abnormalities that parallel focal hand dystonia in a primate model. Somatosens Mot Res 19: 347-357.

Bohannon RW. 1995. Stopwatch for measuring thumbmovement time. Percept Mot Skills 81: 211-216.

Brin MF, Fahn S, Moskowitz C, Friedman A, Shale HM, Greene PE, et al. 1987. Localized injections of botulinum toxin for the treatment of focal dystonia and hemifacial spasm. Mov Disord 2: 237-254.

Butler D. Mobilization of the nervous system. Melbourne, Australia: Churchill Livingston, 1991.

Byl N, Wilson F, Merzenich M, Melnick M, Scott P, Oakes A, McKenzie A. 1996a. Sensory dysfunction associated with repetitive strain injuries of tendinitis and focal hand dystonia: a comparative study. J Orthop Sports Phys Ther 23: 234-244.

Byl N, Hamati D, Melnick M, Wilson F, McKenzie A. 1996b. The sensory consequences of repetitive strain injury in musicians: Focal dystonia of the hand. J Back Musculoskel Rehab 7: 27-39.

Byl N, Merzenich M, Jenkins W. 1996c. A primate genesis model of focal dystonia and repetitive strain injury: I. Learning-induced dedifferentiation of the representation of the hand in the primary somatosensory cortex in adult monkeys. Neurology 47: 508-520.

Byl NN, Merzenich MM, Cheung S, Bedenbaugh P, Nagarajan SS, Jenkins WM. 1997. A primate model for studying focal dystonia and repetitive strain injury: effects on the primary somatosensory cortex. Phys Ther 77: 269-284.

Byl N, Topp KS. 1998. Focal hand dystonia. Phys
Ther Case Rep 1: 39--52.

Byl NN, Nagarajan SS, Newton N, McKenzie AL. 2000. Effect of sensory discrimination training on structure and function in a musician with focal hand dystonia. Phys Ther Case Rep 3: 94-113.

Byl N, McKenzie A, Nagarajan SS. 2000a. Differences in somatosensory hand organization: healthy flutist and flutist with focal hand dystonia. J Hand Ther 13: 301-309.

Byl N, Nagarajan SS, McKenzie A. 2000b. Effectiveness of sensory retraining: three case studies of patients with focal hand dystonia. [Abstract] Society for Neuroscience Meeting, New Orleans, Louisiana, USA.

Byl N, McKenzie A. 2000c. Treatment effectiveness of patients with a history of repetitive hand use and focal hand dystonia: A planned prospective follow up study. J Hand Ther 13: 289-301.

Byl N, Leano J, Cheney LK. 2002. The Byl-CheneyBoczai Sensory Discriminator: reliability, validity, and responsiveness for testing stereognosis. $\mathrm{J}$ Hand Ther 15: 315-330.

Candia V, Elbert T, Altenmuller E, Rau H, Schafer T, Taub E. 1999. Constraint-induced movement therapy for focal hand dystonia in musicians. [Letter] Lancet 353: 42-43.

Carlsson AM. 1983. Assessment of chronic pain. I. Aspects of the reliability and validity of the visual analogue scale. Pain 16: 87-101.

Ceballos-Baumann AO, Sheean G, Pasingham RE, Marsden CD, Brooks DJ. 1995. Cerebral activation with stereotyped writing in patients with writer's cramp before and after botulinum toxin treatment: a PET study. Neurology Suppl 45: 393-396.

Charness ME. 1992. Unique upper extremity disorders of musicians. In: Millender LH, Louis DS, Simmons BP, eds, Occupational Disorders of the Upper Extremity. New York, NY, USA: Churchill Livingstone; 117-151.

Charness M. 1993. The relationship between peripheral nerve injury and focal dystonia in musicians. Am Acad Neurol 162: 21-27.

Chase T, Tamminga C. and Burrows H. 1988. Positron emission tomographic studies of regional cerebral glucose metabolism in idiopathic dystonia. Adv Neurol 50: 237--241.

Chen RS, Tsai CH, Lu CS. 1995. Reciprocal inhibition in writer's cramp. Mov Disord 10: 556-561.

Chen R, Hallett M. 1998. Focal dystonia and repetitive motion disorders. Clin Ortho 351: 102-106. 
Cohen LG, Hallett M. 1988. Hand cramps: clinical features and electromyographic patterns in a focal dystonia. Neurology 38: 1005-1012.

Cole R, Hallett M, Cohen LG. 1995. Double-blind trial of botulinum toxin for treatment of focal hand dystonia. Mov Disord 10: 466-471.

Defendini R, Fahn S. 1988. Magnetic resonance imaging of dystonic states. Adv Neurol 50: 265-275.

DeLong MR, Crutcher MD, Georgopoulis AP. 1985. Primate globus pallidus and subthalamic nucleus: functional organization. J Neurophysiol 53: 530543.

DeLong MR. 1990. Primate models of movement disorders of basal ganglia origin. Trends Neurosci 13: 281-285.

Deuschl G, Toro C, Matsumoto J, Hallett M. 1995. Movement-related cortical potentials in writer's cramp. Ann Neurol 38: 862-868.

Edgelow PI. 1992. Thoracic Outlet Home Program Treatment Kit. Edgelow, Union City, California, USA.

Elbert T, Candia V, Altenmuller E, Rau H, Sterr A, Rockstroh B, et al. 1998. Alteration of digital representations in somatosensory cortex in focal hand dystonia. Neuroreport 9: 3571-3575.

Fahn S, Marsden CD, Calne D. 1987. The treatment of dystonia. In: Marsden CD, Fahn S, eds, Movement Disorders. London, UK: Butterworths; 359-382.

Faure C, Keuss PJG, Lorette G, Vinter A, eds, Advances in Handwriting and Drawing: A Multidisciplinary Approach. Paris, France: Europia; 445-161.

Fung S, Byl N, Melnick M, Callahan P, Selinger A, Ischi K, et al. 1997. Functional outcomes: the development of a new instrument to monitor effectiveness of therapy. Eur J Phys Med Rehabil 7: $31-41$.

Fry H. 1986. Overuse syndromes in musicians 100 years ago: An historical review. Med J Aust 146: 620-625.

Gasser T, Bove C, Ozelius L, Hallett M, Charness M, Hochberg F, et al. 1996. Haplotype analysis at the DYT1 locus in Ashkenazi Jewish patients with occupational hand dystonia. Mov Disord 11: $163-$ 166.

Gerloff Ch, Corwell B, Chen R, Hallett M, Cohen LG. 1998. The role of the human motor cortex in the control of complex and simple finger movement sequences. Brain 121: 1695-1709.

Gilman S unck L, Young A. 1988. Cerebral metabolic activity in idiopathic dystonia studied with positron emission tomography. Adv Neurol 50: 231-236.

Grunewald RA, Yoneda Y, Shipman JM, Sagar HJ. 1997. Idiopathic focal dystonia: a disorder of muscle spindle afferent processing? Brain 120:2179-2185.

Hallett M. 1998. Physiology of dystonia. Adv Neurol 78: 11-18.

Hebb DO. 1949. The Organization of Behavior. New York, NY, USA: Wiley.

Hochberg F, Harris S, Blartert T. 1990. Occupational hand cramps: Professional disorders of motor control. Hand Injury Sports Perform Arts 6: 427-428.

Ikeda A, Shibasaki H, Kaji R, Terado K, Nugamine T, Honda M, et al. 1999. Abnormal sensorimotor integration in writer's cramp: Study of contingent negative variation. Mov Disord 17: 683-690.

Illarioshkin SN, Markova ED, Slominsky PA, Miklena NI, Popovov SN, Limborska SA, et al. 1988. The GTP cyclohydrolase I gene in Russian families with dopa responsive dystonia. Arch Neurol 55: 789-792.

Iwamura Y, Tanaka M, Sakamoto M, Hikosaka O. 1983. Functional subdivisions representing different finger regions in area 3 of the first somatosensory cortex of the conscious monkey. Exp Brain Res 51: 315326.

Iwamura Y. 1992. Dynamic and hierarchical processing in the monkey somatosensory cortex. Biomed Res 14: 107-111.

Jankovic J, Shale H. 1989. Dystonia in musicians. Sem Neurol 9: 131-135.

Jenkins W, Allard T, Nudo R. 1988. Cortical representational plasticity. In: Raskic $\mathrm{P}$, Singer w, eds, Neurobiology of the Neocortex. New York, NY, USA: John Wiley and Sons; 41-67.

Jenkins WM, Merzenich MM, Ochs MT, Allard T, Guic-Robles E. 1990. Functional reorganization of primary somatosensory coretex in adult owl monkeys after behaviorally controlled tactile stimulation. J Neurophysiol 53: 82-104.

Johansson RS. 1996. Sensory control of dexterous manipulation in humans. In: Wing AM, Haggard $P$, Flanagan JR, eds, Hand and Brain. The Neurophysiology and Psychology of Hand Movements. San Diego, California, USA: Academic Press; 381-414.

Juliano SL, Ma W, Eslin D. 1991. Cholinergic depletion prevents expansion of topographic maps in somatosensory cortex. Proc Natl Acad Sci 88: 780-784.

Kaas JH, Merzenich MM, Killackey HP. 1983. The reorganization of somatosensory cortex following 
peripheral nerve damage in adult and developing mammals. Annu Rev Neurosci 6: 325-356.

Kaji R, Rothwell J, Katayama M, Ikeda T, Kubori , Kohara N, et al. 1995. Tonic vibration reflex and muscle afferent block in writer's cramp. Ann Neurol 38: 155-162.

Karp B, Cole R, Cohen L, Grill L, Lou J, Hallet M. 1994. Long-term botulinum toxin treatment of focal hand dystonia. Neurology 44: 70-76.

Katz R, Williams C. 1990. Focal dystonia following soft tissue injury: three case reports with long-term outcome. Arch Phys Med Rehab 71: 345-349.

Kendall F, McCreary E. 1983. Muscles Testing and Function, $3^{\text {rd }}$ Ed. Baltimore, Maryland, USA: Williams Watkins.

Leijnse JNAL. 1997. Anatomical factors predisposing to focal dystonia in the musician's handprinciples, theoretical examples, clinical significance. J Biomech 30: 659-669.

Lenz FA, Byl NN. 1999. Reorganization in the cutaneous core of the human thalamic principal somatic sensory nucleus (Ventral caudal) in patients with dystonia. J Neurophysiol 82: 3204--3212.

Leube B, Rudnicki D, Ratzlaff T, Kessler K, Benecke R, Auburger G. 1996. Idiopathic torsion dystonia: Assignment of a gene to chromosome $18 \mathrm{p}$ in a German family with adult onset, autosomal dominant inheritance and purely focal distribution. Hum Molec Genet 5: 1673-1677.

Liversedge LA, Sylvester JD. Conditioning techniques in the treatment of writer's cramp. Lancet 1955; 1 : 1147-1149.

Liversedge LA, Sylvester JD. 1960. Conditioning techniques in the treatment of writer's cramp. In: Eysenck HJ, ed, Behaviour Therapy and the Neuroses. Oxford, UK: Pergamon Press.

Mai N, Marguardt C. 1994. Treatment of writer's cramp: Kinematic measures as assessment tools for planning and evaluating handwriting training procedures. In: Faure C, Keuss PJG, Lorette G, Vinter $\mathrm{A}$, eds, Advances in Handwriting and Drawing: A Multidisciplinary Approach. Paris, France: Europia.

Mailloux Z. 1990. An overview of the Sensory Integration and Praxis Tests. Am J Occup Ther 44: 589-594.

Marsden CD, Sheehy MP. 1990. Writer's cramp. Trends Neurosci. 13: 148-153.

McKenzie AM. 1997. A new test to measure stereognosis: Key Test. Annual meeting, APTA
California Chapter, Sacramento, California, USA. Abstract.

McKenzie AM, Nagajaran SR, Merzenich MM, Byl NN. 2000. Somatosensory differences in somatosensory evoked responses using magnetic source imaging in patients with focal hand dystonia. Society of Neuroscience Meeting, New Orleans, Louisiana, USA. Abstract.

Merzenich MM, Kaas JH, Wall J, Nelson RJ, Sur M, Felleman D. 1983a. Topographic reorganization of somatosensory cortical areas $3 \mathrm{~b}$ and 1 in adult monkeys following restricted deafferentation. Neuroscience 8: 33-55.

Merzenich MM, Kaas JH, Wall JT, Sur M, Nelson RJ, Felleman DJ. 1983b. Progression of change following median nerve section in the cortical representation of the hand in areas $3 b$ and 1 in adult owl and squirrel monkeys. Neuroscience 10: 639-665.

Merzenich MM, Nelson RJ, Stryker MP, Cynader MS, Schoppmann A, Zook JM. 1984. Somatosensory cortical map changes following digit amputation in adult monkeys. J Comp Neurol 224: 591-605.

Merzenich MM. 1990. Development and maintenance of cortical somatosensory representations: Functional "maps" and neuroanatomical repertoires. In Barnard KE, Brazelton TB, eds, Touch: The Foundation of Experience. Madison, Connecticut, USA: International Universities Press; 47-71.

Merzenich MM, Jenkins WM. 1995. Cortical plasticity, learning, and learning dysfunction. In: Julesz B, Kovacs I, eds, Maturational Windows and Adult Cortical Plasticity. New York, NY, USA: Addison-Wesley; 247-272.

Merzenich M, Wright B, Jenkins W, Xerri C, Byl N, Miller S, Tallal P. 1996a. Cortical plasticity underlying perceptual, motor, and cognitive skill development: implications for neurorehabilitation: Implications for neurorehabilitation. Cold Spring Harbor Symp Quant Biol 61: 1-8.

Merzenich M, deCharms, C. 1996b. Neural representations, experience, and change. In: Llinas, R, Churchland PS, eds, Mind Brain Continuum. Cambridge, Massachusetts, USA: MIT Press; 61-81.

Merzenich MM, Tallal P, Peterson B, Miller SL, Jenkins WM. 1999. Some neurological principles relevant to the origins of-and the cortical plasticity based remediation of-language learning impairments. In: Grafman J, Christen Y, eds, Neuroplasticity: Building a Bridge from the Laboratory to the Clinic. 
Berlin, Germany: Springer Verlag; 169-187.

Mulligan S. 1996. An analysis of score patterns of children with attention disorders on the Sensory Integration and Praxis Tests. Am J Occup Ther 50: 647-654.

Nagarajan SS, Blake DT, Wright BA, Byl N, Merzenich MM. 1998. Practice-related improvements in somatosensory interval discrimination are temporally specific but generalize across skin location, hemisphere, and modality. J Neurosci 18: 1559-1570.

Nakashima K, Rothwell JC, Day BL, Thompson PD, Shannon K. 1989. Reciprocal inhibition between forearm muscles in patients with writer's cramp and other occupational cramps, symptomatic hemidystonia and hemiparesis due to stroke. Brain 112: 681-697.

Naumann M, Reiners K. 1997. Long-latency reflexes of hand muscles in idiopathic focal dystonia and their modification by botulinum toxin. Brain 120: 409-416.

Newmark J, Hochberg F. 1987. Isolated painless manual coordination in 57 musicians. Brit J Neurol Neurosurg Psychiatry 50: 291-295.

Norkin C, Levangie P. 1992. Joint Structure and Function, A Comprehensive Analysis, 2nd ed. Philadelphia, Pennsylvania, USA: Davis FA; 276.

Nudo RJ, Wise BM, SiFuentes F, Milliken GW. 1996. Neural substrates for the effects of rehabilitative training on motor recovery after ischemic infarct. Science 272(5269): 1791-1794.

Nudo RJ, Millikin GW. 1996. Reorganization of movement representations in primary motor cortex following focal ischemic infarcts in adult squirrel monkeys. J Neurophysiol 75: 2144-2149.

Nudo RJ. 1999. Recovery after damage to motor cortical areas. Curr Opin Neurobiol 9: 740-747.

Nudo RJ, Friel KM, Delia SW. 2000. Role of sensory deficits in motor impairments after injury to primary motor cortex. Neuropharmacology 39: 733-742.

Odergren T, Iwasaki N, Borg J, Forssberg H. 1996. Impaired sensory-motor integration during grasping in writer's cramp. Brain 119: 569-583.

Ozelius LJ, Hewett JW, Page CE, Bressman SB, Kramer PL, Shalish C, et al. 1997. The early-onset torsion dystonia gene (DYT1) encodes an ATPbinding protein. Nat Genet 17: 40-48.

Panizza ME, Hallett M, Nilsson J. 1989. Reciprocal inhibition in patients with hand cramps. Neurology 39: 85-89.

Panizza M, Lelli S, Nilsson J, Hallett M. 1990. H- reflex recovery curve and reciprocal inhibition of $\mathrm{H}$-reflex in different kinds of dystonia. Neurology 40: 824-828.

Penfield W, Rasmussen, T. 1950. The cerebral cortex of man: a clinical study of localization of function. New York, NY, USA: MacMillan Publishing.

Perlmutter JS, Stambuk MK, Markham J, Black KJ, McGee-Minnich L, Jankovic J, Moerlein SM. 1997. Decreased $\left[{ }^{18} \mathrm{~F}\right]$ spiperone binding in putamen in idiopathic focal dystonia. J Neurosci 17: 843-850.

Priori A, Pesenti A, Cappellari A, Scarlato G, Barbieri, S. 2001. Limb immobilization for the treatment of focal occupational dystonia. Neurology 57: 405-409.

Pullman SL, Greene P, Fahn S, Pedersen SF. 1996. Approach to the treatment of limb disorders with botulinum toxin A. Experience with 187 patients. Arch Neurol 53: 617-624.

Quartarone A, Girlanda P, Risitano G, Picciolo G, Sinicropi S, Nicolosi C, et al. 1998. Focal hand dystonia in a patient with thoracic outlet syndrome. J Neurol Neurosurg Psychiatry 65: 272-274.

Recanzone GH, Jenkins WM, Hradek GT, Merzenich MM. 1992a. Progressive improvement in discriminative abilities in adult owl monkeys performing a tactile frequency discrimination task. J Neurophysiol 67: 1015-1030.

Recanzone GH, Merzenich MM, Jenkins WM, Grajski KA, Dinse HR. 1992b. Topographic reorganization of the hand representation in cortical area $3 \mathrm{~b}$ of owl monkeys trained in a frequency-discrimination task. J Neurophysiol 67: 1031-1056.

Recanzone GH, Merzenich MM, Jenkins WM. 1992c. Frequency discrimination training engaging a restricted skin surface results in an emergence of a cutaneous response zone in cortical area 3a. J Neurophysiol 67: 1057-1070.

Ridding MC, Sheean G, Rothwell JC, Inzelberg R, Kujirai T. 1995. Changes in the balance between motor cortical excitation and inhibition in focal, task specific dystonia. J Neurol Neurosurg Psychiatry 59: 493-498.

Rijntjes M, Dettmers C, Buchel C, Kiebel S, Frackowiak RS, Weiller C. 1999. A blueprint for movement: functional and anatomical representations in the human motor system. J Neurosci 19: 8043-8048.

Roberts TPL, Poeppel D, Rowley HA. 1998. Magnetoencephalography and magnetic source imaging. Neuropsychiatry Neuropsychol Behav Neurol 11: 49-64.

Rothwell JC, Obeso JA, Day BL, Marsden CD. 1983. 
Pathophysiology of dystonias. Adv Neurol 39: 851-863.

Rowley HA, Roberts TPL. Functional localization by magnetoencephalography. 1995. Neuroimaging Clin North Am 5: 695-710.

Sanger TD, Merzenich MM. 2000. Computational model of the role of sensory disorganization in focal task-specific dystonia. J Neurophysiol 84 : 2458-2464.

Sanger TD, Tarcy DM, Pascual-Leone A. 2001. Abnormalities of spatial and temporal sensory discrimination in writer's cramp. Mov Disord 16: 94-99.

Sherrington CS. 1906. The Integrative Action of the Nervous System, $2^{\text {nd }}, 1947$ Edition. New Haven, Connecticut, USA: Yale University Press.

Spengler F, Roberts TP, Poeppel D, Byl N, Wang X, Rowley HA, Merzenich MM. 1997. Learning transfer and neuronal plasticity in humans trained in tactile discrimination. Neurosci Lett 232: 151-154.

Tempel LW, Perlmutter JS. 1993. Abnormal cortical responses in patients with writer's cramp. Neurology 43: 2252-2257.

Tinazzi M, Frasson E, Bertolasi L, Fiaschi A, Aglioti S. 1999 Temporal discrimination of somesthetic stimuli is impaired in dystonic patients. Neuroreport 10: 1547-1550.

Topp KS, Byl NN. 1999. Movement dysfunction following repetitive hand opening and closing: anatomical analysis in Owl monkeys. Mov Disord 14: 295-306.

Toro C, Deuschl G, Hallett M. 2000. Movementrelated electroencephalographic desynchronization in patients with hand cramps: evidence for motor cortical involvement in focal dystonia. Ann Neurol 47: 456-461.

Tsui J, Bhatt M, Calne S, Calne DB. 1993. Botulinum toxin in the treatment of writer's cramp: a doubleblind study. Neurology 43: 183-185.

Tubiana R, Chamagne P. 1983. [Occupational "cramps" of the upper limb.] Ann Chir Main 2: 134-142.

Tubiana R. 1998. Focal dystonia. Incidence: classi- fication of severity and results of therapy. In Winspur I, Wynn Parry CB, eds, The Musician's Hand. A Clinical Guide. London, UK: Martin Dunitz LTD; 164-167.

Uitti RJ, Vingerhoets FJ, Tsui JK. 1995. Limb dystonia. In: Tsui JK, Calne D, eds, Handbook of Dystonia. New York, NY, USA: Marcel Dekker; 143-158.

van Hilten BJ, van de Beek WJT, Hoff JI, Voormolen JHC, Delhaas EM. 2000. Intrathecal baclofen for the treatment of dystonia in patients with reflex sympathetic dystrophy. N Engl J Med. 343: 625-630.

Wang X, Merzenich MM, Sameshima K, Jenkins WM. 1995. Remodelling of hand representation in adult cortex determined by timing of tactile stimulation. Nature 378(6552): 71-75.

Wang X, Merzenich MM, Sameshima K, Jenkins WM. 1994. Afferent input integration and segregation in learning are input timing dependent. Neuroscience Abstr 20: 1427.

Wilson FR, Wagner C, Hömberg V. 1993. Biomechanical abnormalities in musicians with occupational cramp/focal dystonia. J Hand Ther 6: 298-307.

Wilson FR, Wagner C, Hömberg V. Noth J. 1991. Interaction of biomechanical and training factors in musicians with occupational cramp/focal dystonia. Neurology Suppl 41: 291.

Yang TT, Gallen C, Schwartz B, Bloom FE, Ramachandran VS, Cobb S. 1994. Sensory maps in the human brain [letter] Nature 368: 592-593.

Xerri C, Coq JO, Merzenich MM, Jenkins WM. 1996. Experience-induced plasticity of cutaneous maps in the primary somatosensory cortex of adult monkeys and rats. J Physiol Paris 90: 277-287.

Xerri C, Merzenich MM, Jenkins W, Santucci S. 1999. Representational plasticity in cortical area $3 b$ paralleling tactual-motor skill acquisition in adult monkeys. Cereb Cortex 9: 264-276.

Zirh TA, Reich SG, Perry V, Lenz FA. 1998. Thalamic single neuron and electromyographic activities in patients with dystonia. Adv Neurol 78: 27-32. 

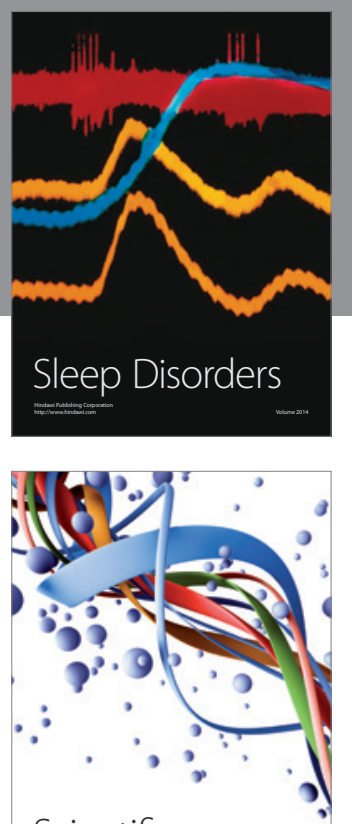

Scientifica
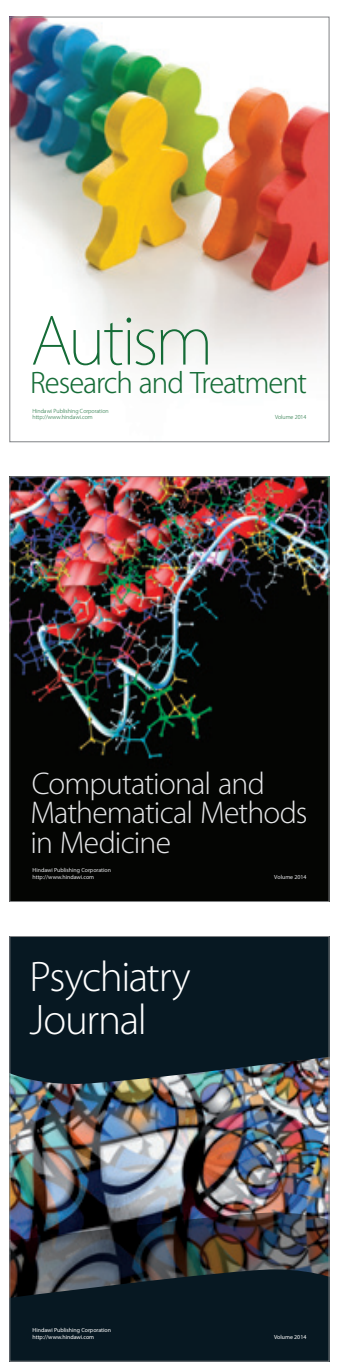
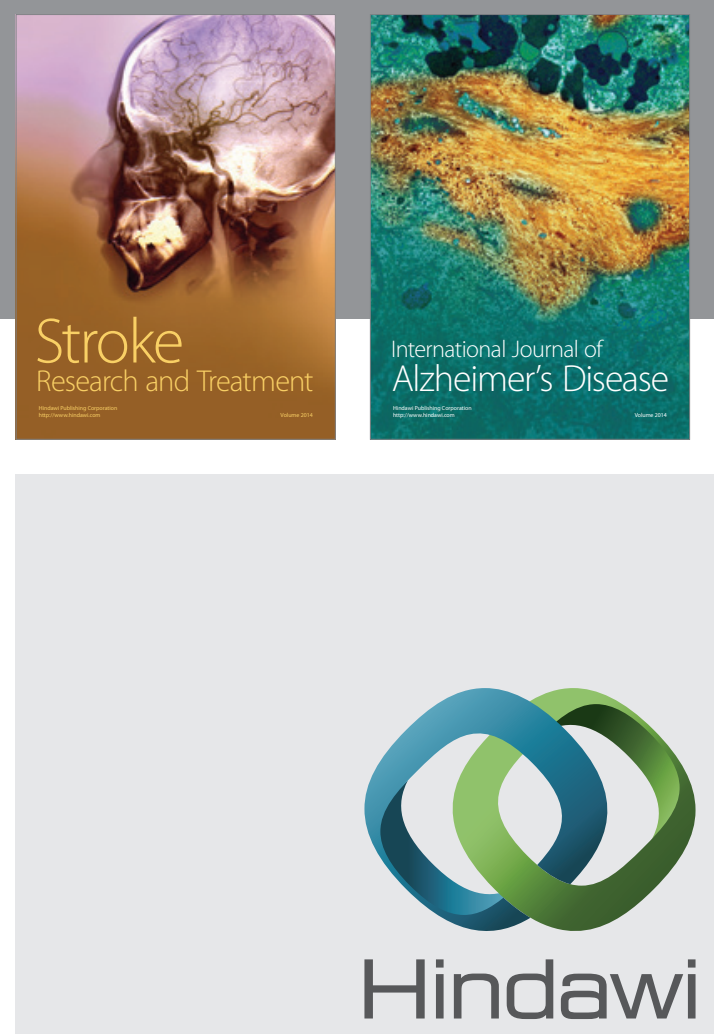

Submit your manuscripts at

http://www.hindawi.com
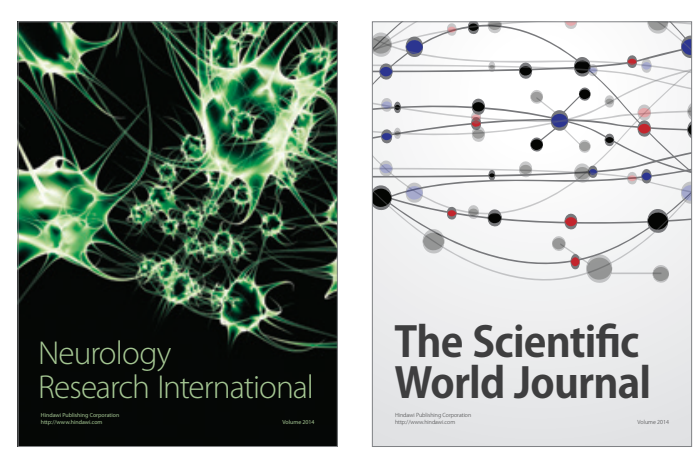

The Scientific World Journal

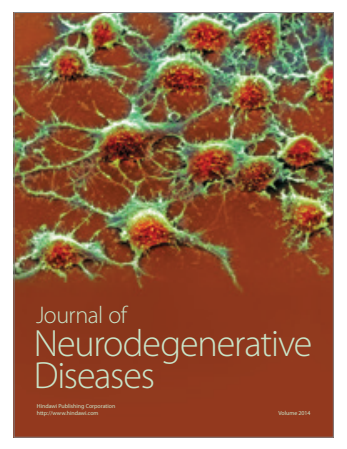

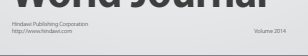

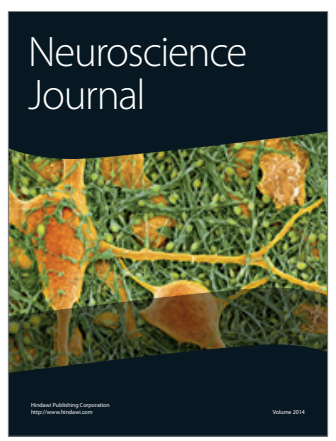

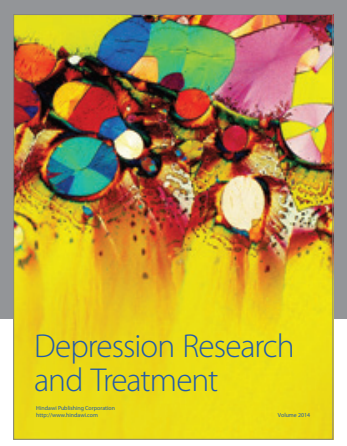
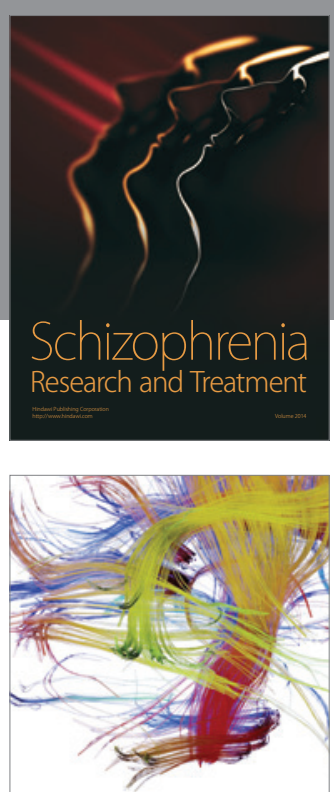

Brain Science

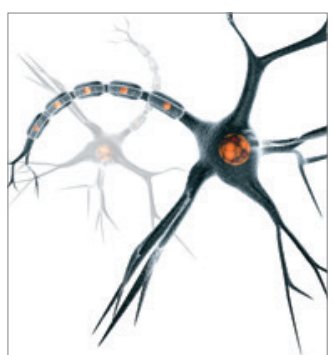

Neural Plasticity
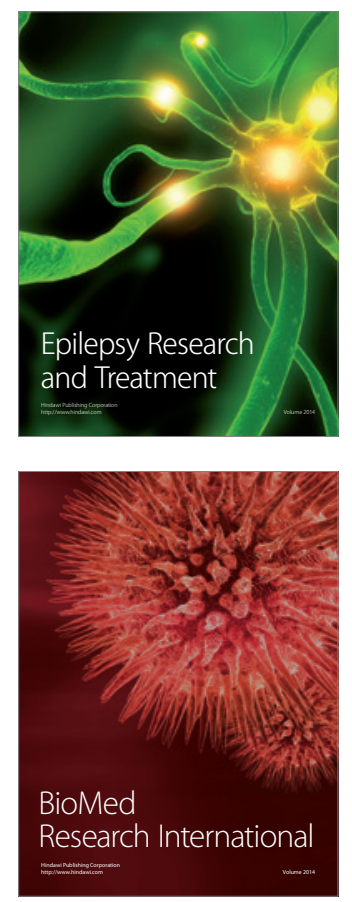

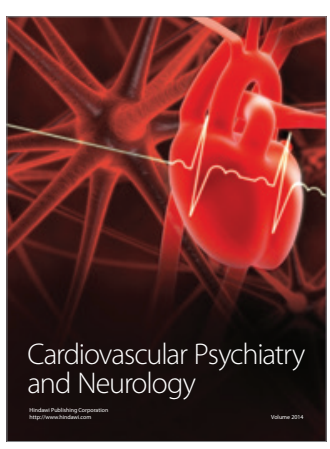

Parkinson's

Disease
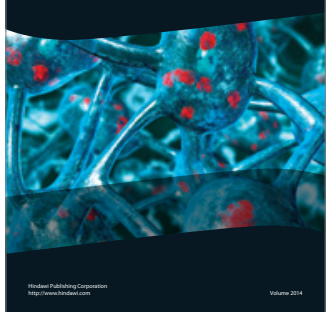